\title{
STATE OF ART ABOUT TRACERS APPLIED IN THE EVALUATION OF WATER LEAKS IN DAMS
}

\author{
PIMENTA, Rafael Colombo ${ }^{1 *}$; BACELLAR, Luís de Almeida Prado²; RJEILLE, Milena Jorge ${ }^{3}$; \\ MOREIRA, Rubens Martins ${ }^{4}$. \\ ${ }^{1,3,4}$ Centro de Desenvolvimento da Tecnologia Nuclear, Serviço de Meio Ambiente, Av. Presidente Antônio \\ Carlos, 6627, Campus da UFMG, Pampulha, CEP 31270-901, Belo Horizonte - MG, Brasil \\ (fone: +55 3130693127 ; fax: +55 3130693174 ) \\ ${ }^{2}$ Universidade Federal de Ouro Preto, Núcleo de Geotecnia, Departamento de Geologia, Escola de Minas, \\ Campus Morro do Cruzeiro, s/n, Bauxita CEP 35400-000, Ouro Preto - MG, Brasil \\ (fone: +55 313559 1600; fax: +55 313559 1600) \\ ${ }^{*}$ Autor correspondente \\ e-mail: colombopimenta@gmail.com
}

Received 05 October 2018; received in revised form 26 October 2018; accepted 27 October 2018

\section{RESUMO}

Barragens são elementos essenciais na infraestrutura e desenvolvimento de um país. Elas são construídas historicamente para armazenar a água, entretanto, atualmente, elas são concebidas para diversas finalidades, como irrigação, disponibilidade de energia, abastecimento de água, retenção de resíduos e controle de enchentes. Todas as barragens do mundo apresentam algum grau de vazamento, ocorrendo através da fundação, do contato com o terreno natural ou na própria barragem. Um dos principais causadores de rompimento de barragem é a erosão interna provocada pelos vazamentos. Traçadores podem ser utilizados no entendimento do fluxo de água na barragem, para que sejam realizadas medidas corretivas visando à diminuição de riscos. No presente estudo foi realizada pesquisa sobre o estado da arte da técnica dos traçadores aplicados às fugas de água em barragens. Foram usadas 78 referências em artigos, publicações $e$ livros e, usando como critérios de inclusão todos os materiais com o tema envolvendo barragens e traçadores aplicados a elas. Este artigo mostra a importância da técnica dos traçadores na detecção precoce de vazamentos para que sejam tomadas providências que garantam a estabilidade da estrutura evitando desastres de danos incalculáveis às populações e ao meio ambiente.

Palavras-chave: Vazamentos; reservatórios; hidrogeotecnia.

\begin{abstract}
Dams are essential elements in infrastructure and country's development. It are historically constructed to store water, however, today dams are built for various purposes, such as irrigation, energy availability, water supply, waste retention, and flood control. All the dams in the world show some degree of leakage, occurring through the foundation, in the contact with the natural terrain or through the dam. One of the main causes of dam rupture is the process of internal erosion caused by leaks. Tracers can be used to understand the water flow in the dam to perform corrective activities to reduce risks. The objective of the study was to research the state of the art of tracers techniques applied to water leakage in dams. We used 78 references, such articles, publications and books, using as inclusion criterion all the materials with the theme involving dams and tracers applied to it. This article reviews these techniques and shows their importance in the early detection of leaks, to realize correct interventions to ensure the stability of the structure, avoiding disasters with incalculable damage to populations and the environment.
\end{abstract}

Keywords: Seepage; reservoir; hydrogeotechnical. 


\section{INTRODUÇÃO}

As barragens e reservatórios têm um papel fundamental nos dias atuais, seja no armazenamento de água para o abastecimento das populações, irrigação, regularização de vazões, prevenção de enchentes, geração de energia elétrica, ou mesmo para a contenção de resíduos industriais e de mineração. Estes empreendimentos podem representar grande risco às populações e ao meio ambiente caso haja seu rompimento (CIGB, 2008).

Praticamente todos os reservatórios construídos no mundo apresentam algum problema de perda de água, e nem sempre é possível prever com precisão o comportamento hidráulico do corpo da barragem e das formações geológicas no seu entorno. Geralmente vazamentos e infiltrações em barragens são previstos no projeto, porém é difícil identificar os riscos associados e as consequências quando excessivos, pois estes podem gerar erosão interna na barragem (piping) e levar à instabilidade da estrutura caso não sejam tomadas as medidas corretivas necessárias (Bedmar e Araguás, 2002). Segundo Panvalkar e Chunade (2017), a detecção de fugas em barragens é um problema complexo concernente ao ramo da Engenharia Geotécnica, havendo várias incertezas relacionadas à caracterização do processo, como heterogeneidade das estruturas hidráulicas, isotropia e não linearidade dos materiais utilizados.

A existência de métodos confiáveis para a detecção de erosão interna é indispensável para antecipar problemas em barragens (Dornstädter e Heinemann, 2012) e a tecnologia dos traçadores pode ser utilizada nestes estudos de forma a confirmar a mistura entre águas, velocidades da água durante a percolação e a interconexão hidráulica existente (Bedmar e Araguás, 2002).

A Agência Internacional de Energia Atômica (IAEA) vem promovendo nas últimas décadas o uso destas técnicas para contribuir na proteção das barragens e melhorar a sua gestão, realizando financiamento de equipes especializadas de cientistas e engenheiros para investigar a fuga de barragens em vários países. Algumas destas publicações merecem destaque, como lbarra et al. (1979), Easey e Hanna (1987), Bedmar et al. (1999), Cordeiro e Plata (1999),
IAEA (2001) e Dung el al. (2007).

Este artigo tem como objetivo a realização de uma pesquisa sobre o atual estado da arte da técnica dos traçadores aplicados ao estudo das fugas de água que ocorrem em barragens. Segundo Ferreira (2002), as pesquisas denominadas "estado da arte" ou "estado do conhecimento" são trabalhos de cunho bibliográfico que trazem o desafio de mapear e discutir a produção acadêmica e científica já realizada sobre um determinado tema para divulgação para a sociedade, facilitando o acesso a informações de diferentes fontes e enfoques, como na identificação de contradições e determinação de lacunas, de modo a se obter uma visão geral acerca do tema em estudo.

Pretende-se desta forma delimitar o tema dos traçadores aplicados ao estudo de barragens, esclarecendo, caracterizando e revelando as múltiplas perspectivas que têm sido usados por pesquisadores ao redor do mundo.

\subsection{Problemas de Fugas em Barragens}

Espera-se um pouco de fuga ou perda de água pelo corpo da barragem, de suas ombreiras ou da fundação (Wright, 1990; Bedmar e Araguás, 2002), e estas perdas devem ser monitoradas por toda a vida útil da estrutura até o seu fechamento (Bedmar e Araguás, 2002; ANA, 2015; Johnson, 1993). Isto porque, o fluxo de água pelo corpo da barragem pode resultar no desenvolvimento de erosão interna (piping), gerando cavidades pelo transporte de material e levar até mesmo a sua ruptura, se não forem tomadas medidas corretivas. A erosão interna é considerada o principal processo causador de rompimentos de barragens de terra envolvendo perdas de vidas e danos a propriedades (Bedmar e Araguás, 2002; Dornstädter e Heinemann, 2012; Wright, 1990; Johnson, 1993; FEMA, 2015).

De acordo com Deshpande e Panvalkar (2018), são muitas as causas dos vazamentos em barragens, dependendo do tipo construtivo destas estruturas. Em barragens de terra estas fugas podem ocorrer principalmente pelo aterro, fundação ou ombreiras, e serem causadas devido a problemas no filtro, má compactação, rachaduras, entre outros. Em barragens de concreto os vazamentos são causados devido a 
falhas construtivas, dissolução do cimento, erosão, rachaduras entre outras causas.

\section{MATERIAIS E MÉTODOS}

Para se alcançar o objetivo proposto foi realizado um levantamento bibliográfico seletivo, restrito aos estudos publicados nesta área do conhecimento. Foram utilizadas pesquisas em fontes bibliográficas, como artigos científicos, manuais, informativos, teses e dissertações sobre o tema dos traçadores aplicados em estudos de fugas em barragens.

As bases de acesso de dados utilizadas para consultas dos artigos foram, principalmente, Portal de Periódicos da Coordenação de Aperfeiçoamento de Pessoal de Nível Superior (CAPES), Research Gate e Springer Link. Nessas ferramentas de pesquisas foi possível encontrar diversos artigos, publicações de congressos e também capítulos de livros. Para tais pesquisas, foi usado como critério de inclusão todas as fontes que tratam o tema de traçadores aplicados à barragens, ou fazem menção à esta tecnologia. Todas publicações que possuíam o tema de interesse foram incluídos no dado estudo. Desta forma, para compor essa compilação do estado da arte foram usadas 78 referências bibliográficas, sendo a maioria delas, escritas na língua inglesa.

\section{RESULTADOS}

\subsection{Definição, Abordagem, Classificação e Características dos Traçadores}

Davis et al. (1985) tratam os traçadores como uma massa ou energia transportados pelas águas e que podem gerar informações sobre a direção do movimento e/ou a velocidade destas águas. Podem ser classificados como traçadores ambientais, ou seja, aqueles já presentes no ambiente, ou traçadores intencionais, quando injetados no sistema hidrológico com o objetivo de estudar as características deste sistema (Leibundgut et al., 2009; Pimenta, 2016).

A abordagem convergente de sistemas de Leibundgut et al. (2009) pode ser aplicada ao estudo em barragens através de traçadores. Conforme a Figura 1, a entrada deste sistema é representada matematicamente pela infiltração/injeção de traçadores na área da barragem através de variáveis conhecidas em função do tempo, como volume, energia e concentração. O sistema da barragem processa as variáveis por meio do transporte dos traçadores e a decodificação destas variáveis na saída do sistema fornece indicações sobre os processos que governam o fluxo de água na barragem.

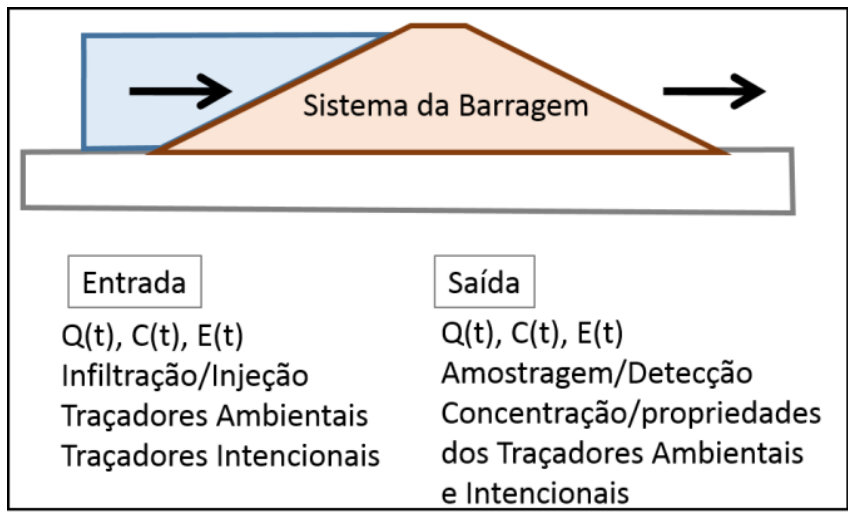

Figura 1. Representação da abordagem de sistema para os traçadores aplicados em estudos de fluxo de água em barragens.

\subsection{Traçadores Ambientais}

Entende-se por traçadores ambientais os componentes que estão presentes no ciclo hidrológico e que podem gerar informações sobre este ciclo. Estes traçadores podem ser isótopos estáveis, isótopos radioativos, parâmetros químicos e físico-químicos da água e, por vezes, poluentes de origem antrópica (Leibundgut et al., 2009; Pimenta, 2016).

\subsubsection{Parâmetros Físico-Químicos}

\subsubsection{Temperatura}

A medição da temperatura da água tem sido usada desde 1950 para monitorar a infiltração de barragens por medidas manuais (FEMA, 2015). Dornstädter e Heinemann (2012) e Constantz et al., (2008) concluíram que a temperatura da água é um ótimo traçador para investigação de fugas em barragens. Havendo uma diferença entre a temperatura da água em superfície e a subterrânea, a água superficial ao percolar a barragem irá provocar anomalias na temperatura, funcionando desta forma como um traçador, mesmo em velocidades extremamente baixas, podendo detectar o processo de erosão interna precocemente.

Os gradientes de temperatura ocorrem 
permanentemente ou sazonalmente, formando flutuações de temperatura nas áreas prováveis onde ocorre a infiltração. A temperatura é transportada por meio da convecção e se propaga na barragem, alterando o campo de temperaturas típicas da água de percolação (Aufleger et al., 2007).

As medições de temperatura começaram a ganhar maior aceitação nos anos de 1990 quando cabos de fibra ótica foram desenvolvidos para detectar mudanças térmicas ao longo do comprimento do cabo. De acordo com Aufleger et al. (2007), a medição da temperatura é uma ferramenta poderosa para detectar vazamentos em estruturas hidráulicas, existindo uma enorme potencial para a melhoria da eficácia desta técnica, que segundo o autor, será uma tecnologia chave no monitoramento de barragens no futuro.

Segundo Dornstädter (2013), existem três principais técnicas de medição da temperatura in situ nas barragens, que são: as sondas; os sensores de temperatura distribuídos com fibra ótica; e o método de pulso de calor (HPM). As sondas são utilizadas para medir a temperatura da água profundidades de até 40 metros e a técnica se baseia em tubos metálicos, contendo correntes de sensores de temperatura, acumulados no solo. As temperaturas medidas são imediatamente mapeadas e o espaçamento inicial das sondas pode ser reduzido nas regiões onde as anomalias de temperatura são detectadas.

Já a segunda técnica ocorre por meio do envio de um curto pulso de laser por uma fibra ótica, tornando possível a obtenção de um perfil de temperatura distribuído ao longo de toda essa fibra e com isso, determinar a zonas de infiltração na barragem. Esse sensoriamento permite medições de temperatura de alta resolução em uma extensão de até $30 \mathrm{~km}$.

Por fim, o Método do Pulso de Calor foi desenvolvido para medir as condutividades térmicas locais e para estimar as velocidades da água infiltrada nas barragens. Ele baseia-se na geração de uma perturbação térmica do solo, representada por uma fonte de calor de linha, que pode ser realizada com fios elétricos. A partir de 1991, a fonte de calor da linha foi combinada com sondas de temperatura, em que os fios elétricos foram inseridos nos tubos metálicos. No momento em que a fonte de calor for ligada, as temperaturas dentro do dispositivo de medição subirão rapidamente e, no caso de condução térmica, elas aumentarão constantemente em uma escala de tempo logarítmica. Dessa forma, quanto maior a velocidade nos poros, maior será a dissipação de calor, e menor será a temperatura final detectada.

Dornstädter (2013) realizou um estudo na barragem Knezevo, localizada a leste da capital da Macedônia, Skopje. O autor utilizou da técnica do cabo de fibra ótica para detecção de vazamento na barragem. Foi possível observar que em dois locais das barragens há anomalias significativas de temperatura, que indicariam uma infiltração continua e prováveis pontos de vazamento da barragem. As características apresentadas sugeriram que as anomalias foram causadas pelo aumento do nível de água do reservatório.

A temperatura também foi usada como traçador no estudo feito por Johansson e Sjödahl (2004) na Noruega, na barragem de teste Røsvatn Field. As medições foram realizadas ao longo do pé da barragem usando 23 sensores de alta precisão (Greisinger PT100), a fim de estimar a mudança de temperatura e para detectar a vazão de escoamento pelo dique. Os autores encontraram quatro áreas de fugas significativas, entretanto as temperaturas medidas no pé da barragem não foram capazes de determinar exatamente em qual porção do núcleo o vazamento estava localizado, visto que estavam indicando a localização ao longo da barragem. Para ser possível ter certo conhecimento sobre o nível desses vazamentos, houve a alteração de algumas condições durante o enchimento, proporcionando essa estimativa da elevação do ponto de fuga.

Nygren (2013) estudou vazamentos em barragem de terra Ledinge na Suécia utilizando a temperatura como traçador. A medida da temperatura foi realizada por cabos de fibra ótica. Este autor apresentou e comparou três diferentes métodos computacionais de análise dos dados de temperatura registrados. Foi concluído que os métodos da Soma dos Senos e da Comparação das Inclinações são úteis para o registro de mudanças abruptas de temperatura, podendo desta forma serem utilizados como parâmetro indicador para o acionamento de alarmes para os responsáveis pelo monitoramento da barragem.

De acordo com Aufleger et al. (2007), a modelagem de fluxo tridimensional é uma das principais ferramentas a serem empregadas para a análise das medidas de temperatura 
registradas em campo. As simulações realizadas por estes pesquisadores permitiram caracterizar o processo de propagação das anomalias térmicas e também identificar processos hidráulicos e parâmetros térmicos que participam do fenômeno. A Figura 2 apresenta uma seção extraída de um modelo de fluxo 3D pelo método de diferenças finitas. Pode-se observar distribuição de temperatura para condições normais de percolação, e uma comparação para a situação com vazamentos induzidos por fraturas na camada impermeável abaixo da barragem.

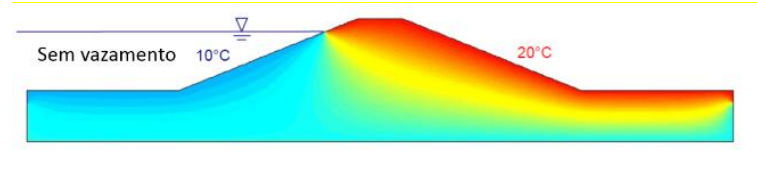

Temperatura

Com vazamento

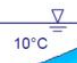

$\stackrel{\nabla}{\underline{\nabla}}$
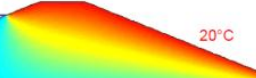

Figura 2. Distribuição da temperatura em uma seção de um dique homogêneo. Simulação em modelo numérico realizado em Feflow para duas condições distintas. Modificado de Aufleger et al. (2007).

\subsubsection{Condutividade Elétrica}

A condutividade elétrica (C.E.) é um traçador natural e sua medição pode gerar importantes informações na avaliação das fugas de barragens e reservatórios (Contreras e Hernández, 2010). É uma função direta dos íons dissolvidos na água (Appelo e Postma, 2006), fazendo com que diferentes meios imprimam nas águas subterrâneas sua característica química, de acordo com os minerais presentes nos aquíferos.

A C.E. é facilmente medida com um condutivímetro, e pode ser determinada na água do reservatório da barragem, ao longo de coluna de água em poços e em surgências de água à jusante do barramento. O acompanhamento da C.E. pode trazer indícios sobre a origem e mistura de diversas águas (Pimenta, 2016).

Assim como no caso da temperatura, os reservatórios de água desenvolvem uma estratificação salina, fazendo que as águas mais profundas tenham maior salinidade, e, portanto maior condutividade elétrica, do que as águas mais rasas (Contreras e Hérnandez, 2010).

Contreras e Hérnandez

(2010) recomendam que a investigação de condutividade elétrica e temperatura sejam incluídas nas fases iniciais de todos os estudos de vazamentos em barragens. Estes autores indicam também 0 uso de sondas de termocondutividade que medem simultaneamente a temperatura e a condutividade elétrica da água, devendo ser incluídos nos planos de investigação perfis verticais de condutividade elétrica e temperatura no lago do reservatório. Na figura 3 é possível observar perfis desses dois parâmetros da barragem no Wyoming.

As medidas de condutividade elétrica da água podem variar muito durante as estações do ano, sendo comum a observação de menores condutividades elétricas durante a estação chuvosa devido ao maior aporte de águas do escoamento superficial, e maiores condutividades elétricas durante a estação seca do ano, devido a uma maior contribuição das águas subterrâneas para as águas do reservatório (Contreras e Hérnandez, 2010).

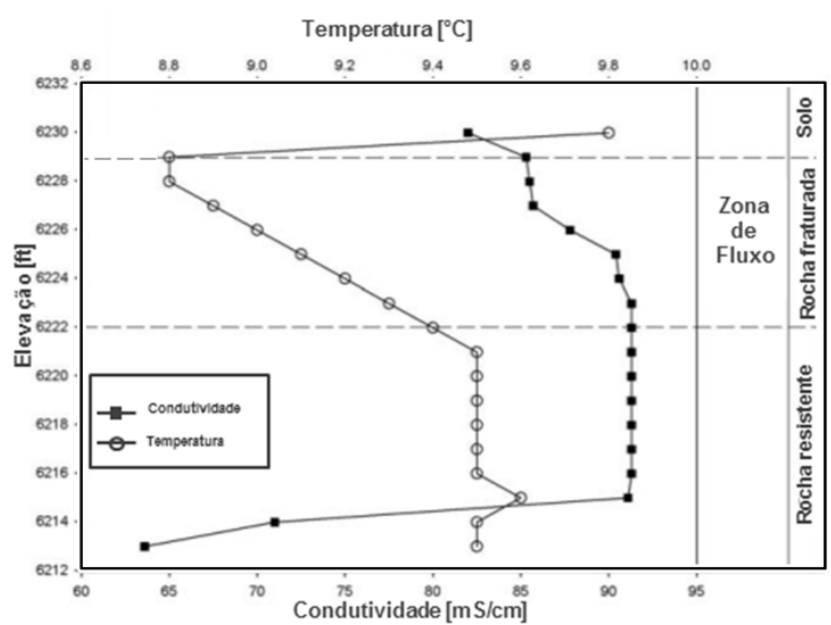

Figura 3. Perfis de Condutividade Elétrica e de Temperatura em poço totalmente revestido em barragem no Wyoming. Modificado de Contreras e Hérnandez (2010).

A medição de C.E. e de $\mathrm{pH}$ medidos in situ foi utilizada por Valencia et al. (2011) com o objetivo de complementar os resultados da injeção de traçador radioativo e verificar a interconexão entre as águas da barragem de rejeitos e a drenagem de fundo.

\subsubsection{Hidroquímica}

A análise da composição química da água é uma ferramenta muito útil na identificação da origem da água percolada, e pode ser usada 
para classificar a água em diferentes fácies hidroquímicas, facilitando distinção das águas do reservatório com as do aquífero.

Craft (2005) estabeleceu os procedimentos para estudos dos vazamentos em barragens por meio da análise química da água. Este autor utilizou o termo química da infiltração para designar o conjunto de concentrações medidas dos constituintes químicos na água de infiltração. Craft (2005) destaca ainda que a avaliação da infiltração não é simples, podendo ter interferência de processos químicos concorrendo simultaneamente, como a dissolução mineral, misturas de águas durante a infiltração, existência de águas da etapa anterior à construção do barramento, demora na chegada da água do reservatório ao local de amostragem, ou mesmo processos biológicos, principalmente por microorganismos. A Figura 4 representa 0 perfil ilustrativo da mistura entre águas provenientes do reservatório com águas do aquífero.

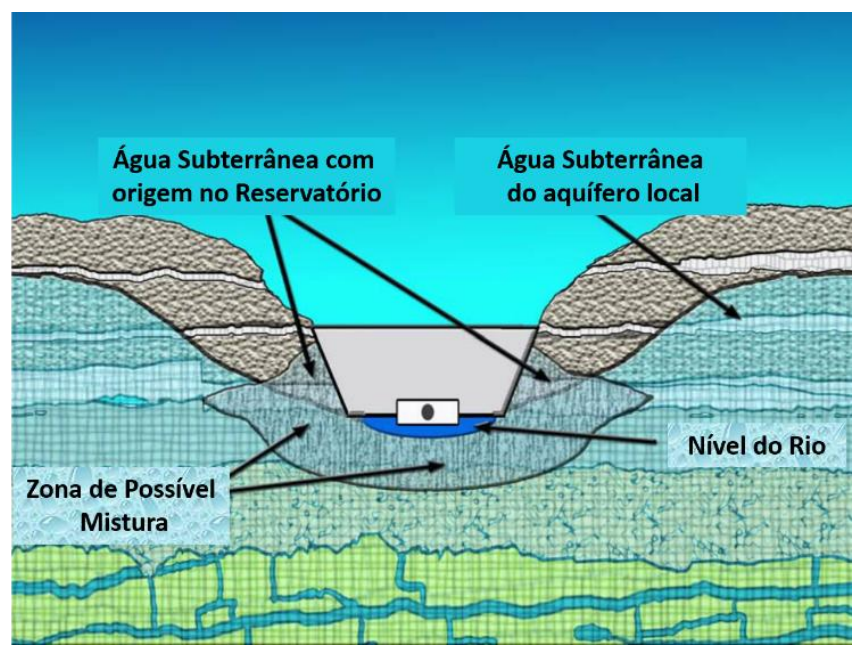

Figura 4. Vista de seção esquemática de jusante para montante de uma barragem mostrando um cenário de mistura entre a água subterrânea proveniente do reservatório e a água subterrânea do aquífero. Modificado de Craft (2005).

Em estudo sobre a proporção existente entre as águas do reservatório com águas subterrâneas presentes a jusante da barragem de rejeitos da mina Nickel Plate, no Canadá, Ghomshei e Allen (2000) utilizaram os sulfatos dissolvidos na água como um traçador indicativo do processo de infiltração atribuído ao eventual vazamento na barragem. O sulfato foi escolhido como traçador devido a sua alta concentração no reservatório, e por se comportar relativamente como um traçador conservativo, ou seja, não sofre reações ou retenções durante o fluxo, e por último, por estar presente em baixas concentrações nas águas receptoras. Os autores concluíram que a água analisada tem uma proporção entre águas naturais e de infiltração de cerca de $50 \%$.

Variações qualitativas da água entre o reservatório e a água de infiltração podem ser visualizadas em diagramas hidroquímicos, como os de Piper, Stiff, e em Radar (Craft, 2005). Estes diagramas são simples e facilitam a visualização de vários parâmetros químicos simultaneamente, ajudando no reconhecimento de similaridade entre diferentes tipos de águas. A Figura 5 apresenta a separação de duas fácies hidrogeoquímicas utilizando o diagrama de Piper.

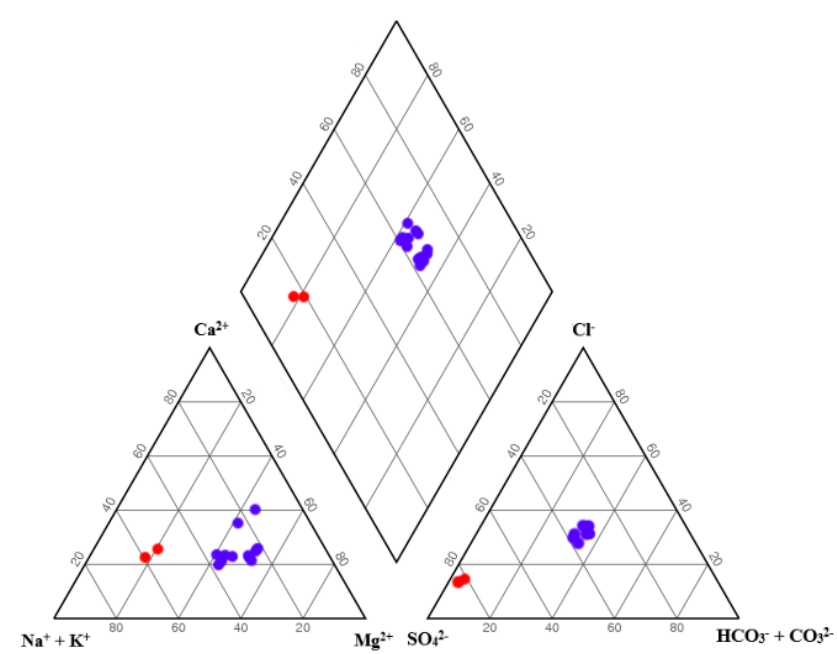

Figura 5. Diagrama de Piper mostrando duas fácies hidrogeoquímicas (uma em azul e outra em vermelho) na ombreira esquerda da hidrelétrica de Xiaolangdi na China. Modificado de Fan et al. (2012).

Quando os solutos tem maior concentração nas águas da infiltração, não significa necessariamente que esteja havendo uma dissolução de minerais durante o fluxo da água. Segundo Craft (2005) outros fatores também devem ser avaliados, como processos bacterianos, trocas iônicas em argilas e misturas de diferentes águas. Estes fatores devem ser levados em consideração antes de concluir precipitadamente que esteja havendo dissolução de minerais e formação de vazios.

Ao início do processo de fluxo em ambiente subterrâneo, a atividade microbiológica se dá de forma previsível seguindo diversas etapas através da transição do ambiente oxidante para o ambiente redutor:

a) Diminuição do Oxigênio Dissolvido 
(OD) por bactérias aeróbicas que oxidam o carbono orgânico e reduzem $0 \mathrm{O}_{2}$ da solução. Os valores de Eh são sempre positivos enquanto houver OD;

b) Redução e denitrificação do nitrato $\left(\mathrm{NO}_{3}{ }^{-}\right)$através da respiração de bactérias como Aeromonas, Enterobacter e Acaligenes pela reação química:

$\mathrm{NO}_{3}^{-}+0,5 \mathrm{C}_{\text {orgânico }} \rightarrow \mathrm{NO}_{2}^{-}+0,5 \mathrm{H}_{2} \mathrm{O}+0,5 \mathrm{CO}_{2}$ (eq.1)

A denitrificação ocorre em condições anaeróbicas como a Paracoccus denitrificans. Este processo reduz o nitrato por completo para o gás $\mathrm{N}_{2}$, que pode voltar à atmosfera caso a infiltração esteja ocorrendo próximo à superfície. Valores típicos de Eh estão entre 0 e $-100 \mathrm{mV}$.

c) Redução dos oxihidratos de Ferro e Manganês pela respiração de bactérias Bacillus, Pseudomonas e Proteus, em ambiente com depleção do oxigênio dissolvido e o do nitrato. Valores típicos de Eh entre $-50 \mathrm{mV}$ e $-200 \mathrm{mV}$.

d) Redução do sulfato para gás sulfídrico $\left(\mathrm{H}_{2} \mathrm{~S}\right)$ pelas bactérias Desulfovibrio, Desulfotomaculum e Desulfobacter. Os valores de Eh variam de $-200 \mathrm{mV}$ a $-300 \mathrm{mV}$, geralmente as condições mais severas de redução observadas em fugas de barragens.

e) Redução do $\mathrm{CO}_{2}$ para metano por bactérias como Methanobacterium que utiliza $\circ \mathrm{C}$ do $\mathrm{CO}_{2}$ e $\mathrm{HCO}_{3}$ para produzir $\mathrm{CH}_{4}, \quad$ em ambiente estritamente anaeróbico. Valores de Eh variam de $-350 \mathrm{mV}$ a $-450 \mathrm{mV}$, condições redutoras severas raramente observadas em fugas de barragens.

Outro fator importante a se considerar é a troca iônica que pode ocorrer na superfície de argilominerais (Craft, 2005). Os argilominerais são aluminosilicatos formados por delgadas camadas mantidas unidas por íons como $\mathrm{Ca}, \mathrm{Mg}$, $\mathrm{Na}$ e K. Craft (2005) apresenta o exemplo da troca iônica entre a água contendo altas concentrações de $\mathrm{Ca}$ com relação ao $\mathrm{Na}$. Neste caso, pode ocorrer a troca do $\mathrm{Ca}$ pelo $\mathrm{Na}$ no argilomineral montmorilonita sódica, aumentando a concentração de $\mathrm{Na}$ na água de infiltração e diminuindo a concentração do $\mathrm{Ca}$.

\subsubsection{Turbidez}

Oliveira (2008) indica a turbidez nas águas como um parâmetro importante a ser verificado nas inspeções rotineiras em pequenas barragens. Segundo este autor o aumento na turbidez da água percolada pode estar relacionado a: abatimentos; recalques; erosões e trincas no maciço; ruptura cisalhante vertical da crista da barragem; fluxo sob uma barragem de concreto sem drenos; e depressões na crista.

Wright (1990) cita que entre outros fatores, o aumento da turbidez na água do vazamento do reservatório pode indicar risco as condições de segurança.

Em estudo realizado em uma barragem de terra no rio Kama, na Rússia, Maksimovich et al. (2016) concluíram que o índice de turbidez não é somente um traçador do processo de erosão interna, mas também um indicador da atividade microbiológica que ocorre no interior do barramento devido ao aporte de matéria orgânica no reservatório. Segundo estes autores, a existência de microrganismos pode alterar as propriedades físicas e mecânicas dos solos, causando efeitos negativos à estabilidade da estrutura.

\subsubsection{Isótopos Estáveis}

Os isótopos estáveis são usados para identificar águas de diferentes origens, padrões de fluxo, evolução geoquímica, interconexões hidráulicas e proporção entre misturas (Clark e Fritz, 1997). A análise destes traçadores em barragens irá mostrar um contraste isotópico entre as diferentes águas na área de estudo, como águas do reservatório, águas subterrâneas, e possíveis misturas em surgências a jusante da barragem (Bedmar e Araguás, 2002). Portanto, os isótopos estáveis desempenham um importante papel nos estudos de fugas de água em barragens (Ba et al. 2014).

\subsubsection{Deutério e Oxigênio-18}

Os isótopos estáveis ${ }^{2} \mathrm{H}$ (deutério) e ${ }^{18} \mathrm{O}$, por fazerem parte da molécula de água, são considerados como traçadores ideais de águas, 
podendo identificar águas de diferentes fontes (Clark e Fritz, 1997). Durante o ciclo hidrológico a composição isotópica da água se altera nos diversos ambientes e processos a que é submetida. Este fracionamento ocorre durante a mudança de fase da água, ou durante reações químicas e é denominado fracionamento isotópico (Clark e Fritz, 1997).

Os isótopos estáveis ${ }^{2} \mathrm{H}$ e ${ }^{18} \mathrm{O}$ são reportados na forma da notação delta (ס), expressando os valores em relação a um padrão de referência, e geralmente expressos em \%o (partes por mil), sendo um parâmetro adimensional (Clark e Fritz, 1997; Mook, 2000). A Equação 2 e 3 apresentam o cálculo para a determinação de $\delta$. É aceito o padrão de referência VSMOW (Vienna Standard Mean Ocean Water), que está próxima da composição isotópica média da água do mar (Clark e Fritz, 1997; Mook, 2000; Santiago et al., 2008). Craig (1961, in Clark e Fritz, 1997), propôs a reta meteórica mundial dada pela relação entre $\delta^{18} \mathrm{O}$ e $\delta^{2} \mathrm{H}$ as águas pluviais em diversos locais do globo. Nesta representação gráfica, apresentada na Figura 6, é possível observar as variações destes isótopos nas águas em vários compartimentos da hidrosfera em relação ao padrão VSMOW, tornando possível desta forma a identificação da origem de águas na investigação de infiltrações em barragens.

$$
\begin{aligned}
& \delta^{18} O=\left(\frac{R}{R r}-1\right) \times 1000 \% 0 \\
& \delta^{2} \mathrm{H}=\left(\frac{R}{R r}-1\right) \times 1000 \% 0
\end{aligned}
$$

Onde:

$\delta$ - Desvio da razão isotópica da amostra em relação a um padrão de referência;

$\mathrm{R}$ - Razão isotópica da amostra;

$\mathrm{Rr}$ - Razão isotópica do padrão de referência.

Para identificação das fontes de vazamento nas galerias de drenagem da barragem Tehri na Índia, Rai et al. (2012) utilizaram os isótopos estáveis ${ }^{2} \mathrm{H}$ e ${ }^{18} \mathrm{O}$ nas águas coletadas no reservatório, nascentes e nos pontos de vazamento. Concluiu-se que a água da infiltração é uma mistura entre as águas do reservatório com as águas subterrâneas, e que a proporção das águas do reservatório sobre as águas da infiltração é maior durante o período das monções onde o nível do reservatório é maior.

Dung et al. (2006) analisaram mensalmente $0 \quad{ }^{2} \mathrm{H}$ e $\quad 0 \quad{ }^{18} \mathrm{O}$ em alguns piezômetros e nas águas do reservatório de uma barragem no Vietnam. Foi confirmada a presença de águas provenientes do reservatório, de águas subterrâneas e também de águas percoladas pela barragem. Pela variação mensal destes parâmetros foi possível determinar os tempos de trânsito da água entre o reservatório e os pontos de observação. A Figura 6 apresenta os resultados das análises de $\delta^{2} \mathrm{H}$ e $\delta^{18} \mathrm{O}$ em comparação com a reta meteórica mundial (GMWL - Global Meteoric Water Line).

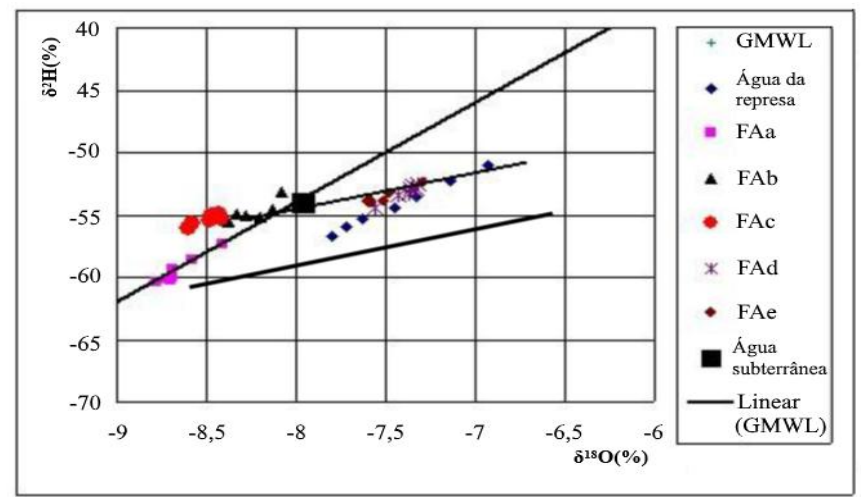

Figura 6. Fracionamento isotópico das amostras de água em barragem. Notar semelhança da composição isotópica da água dos piezômetros

FAd, FAe com as águas da represa e a semelhança entre as águas dos demais piezômetros com as águas pluviais e subterrâneas. Modificado de Dung et al. (2006).

Peng e Wang (2008) empregaram isótopos estáveis para a verificação da causa e a origem da água de um vazamento anormal na barragem de terra zonada do reservatório de XinShan localizado ao norte de Taiwan. A Figura 7 apresenta uma comparação para os isótopos estáveis entre as estações quentes e frias do ano. Nota-se que há diferenças na composição isotópica nas estações quentes e frias. Estas características indicam que durante o período chuvoso há maior depleção destes isótopos devido ao efeito da quantidade de chuvas. Estes resultados puderam ajudar a compreender o tempo de residência das águas pluviais no sistema da barragem. 

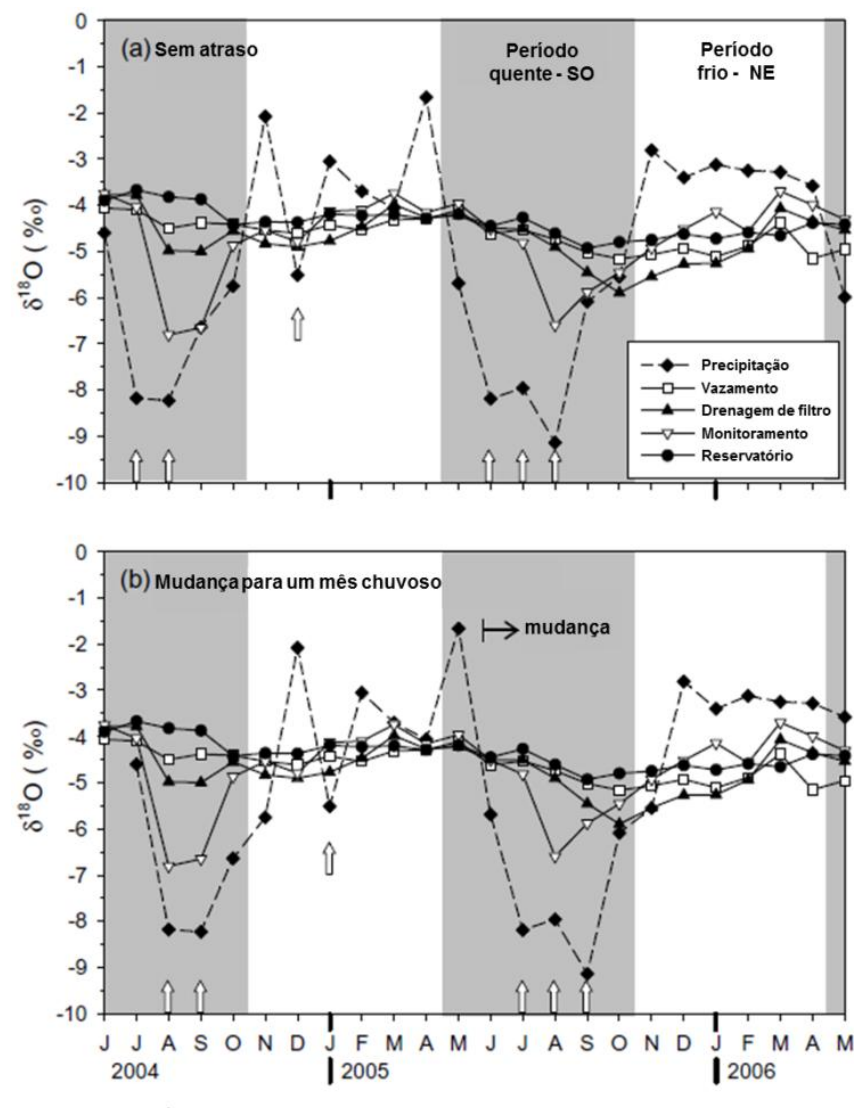

ก Eventos chuvosos pesados de tufões

Figura 7. Comparação entre as médias ponderadas das composições isotópicas e de precipitação durante um período de dois anos na barragem de Xin-Shan em Taiwan. Extraído de Peng e Wang (2008).

\subsubsection{Carbono-13}

Segundo Bedmar et al. (1999), a razão isotópica ${ }^{13} \mathrm{C} /{ }^{12} \mathrm{C}$ no Carbono Inorgânico Dissolvido é utilizada com sucesso para investigar problemas de fugas em muitas barragens localizados em climas temperados e tropicais. A maioria das águas superficiais é caracterizada por um enriquecimento relativo da ${ }^{13} \mathrm{C}$, desde que esteja em equilíbrio com a composição isotópica do $\mathrm{CO}_{2}$ atmosférico. Por outro lado a água subterrânea é caracterizada por valores de ${ }^{13} \mathrm{C}$ mais negativos, resultando em um expressivo contraste isotópico entre os dois tipos de água.

$\mathrm{O} \mathrm{CO}_{2}$ dissolvido nas águas subterrâneas induz a dissolução do carbono do solo, visto que essa adição vai deslocar o $\mathrm{pH}$ para valores mais ácidos e com isso, aumenta-se a capacidade de dissolução dos carbonatos pelas águas subterrâneas. Após a reação ocorrida entre o carbono presente no solo, o $\mathrm{CO}_{2}$ e água, o pH aumenta e o bicarbonato $\left(\mathrm{HCO}_{3}\right)$ e carbonato
$\left(\mathrm{CO}_{3}{ }^{-2}\right)$ passam a predominar nas espécies de Carbono Inorgânico Dissolvido (CID) (Bedmar e Araguás, 2002).

Uma das espécies isotópicas presentes no $\mathrm{CID}$ é ${ }^{13} \mathrm{C}$, sendo sua distribuição controlada pelo $\mathrm{pH}$. Dessa forma, a partir das diferentes reações do CID, é possível determinar as razões isotópicas do ${ }^{13} \mathrm{C}$, observando os enriquecimentos ou empobrecimentos da espécie no sistema.

Alguns estudos feitos para identificar a origem de nascentes emergentes em represas, na Costa Rica (Reservatório El Arenal), Cuba (Reservatório La Herradura) e Espanha (Reservatório Arquillo de San Blas), utilizaram da técnica de ${ }^{13} \mathrm{C}$, medindo-se o $\delta^{13} \mathrm{C}$ no CID. No geral, nos três estudos realizados, nas amostras dos pontos críticos em que ocorria vazamento, não foi verificada relação com a água dos reservatórios. Isso porque foi registrado que nas amostras coletadas nas proximidades da barragem são significativamente mais empobrecidas em $\delta^{13} \mathrm{C}$ do que as observada nas águas do reservatório. Estes resultados provaram que as águas analisadas nos vazamentos não eram provenientes dos reservatórios das barragens (Cordero e Plata, 1999; Bedmar e Araguás, 2002).

Agudo et al. (2000) em estudo com a participação do Centro de Desenvolvimento da Tecnologia Nuclear (CDTN), empregaram a técnica de isótopos estáveis na investigação dos possíveis vazamentos através da formação geológica na Represa de Tapacurá, próxima a cidade de Recife, Brasil. As amostras foram coletadas do reservatório e de vários pontos de coleta a jusante, sendo elas analisadas quanto às suas concentrações ${ }^{13} \mathrm{C}$ e também deutério e ${ }^{18} \mathrm{O}$. A comparação entre os resultados dessas análises indicou que a água do reservatório e dos outros pontos de coleta era proveniente de origens distintas. $\mathrm{Em}$ relação, ao ${ }^{13} \mathrm{C}$, os valores $\delta^{13} \mathrm{C}$ encontrados estão apresentados na Figura 8. As amostras do Reservatório e da Galeria da Represa mostram um $\delta^{13} \mathrm{C}$ logo abaixo do padrão para águas superficiais, pois está em equilíbrio com o $\mathrm{CO}_{2}$ atmosférico. Enquanto que as outras amostras apresentaram valores muito menores. Esta é uma indicação de que $\circ \mathrm{HCO}_{3}$ dissolvido nessas águas é de origem do solo, sendo, portanto provenientes de águas subterrâneas não provenientes do reservatório. 


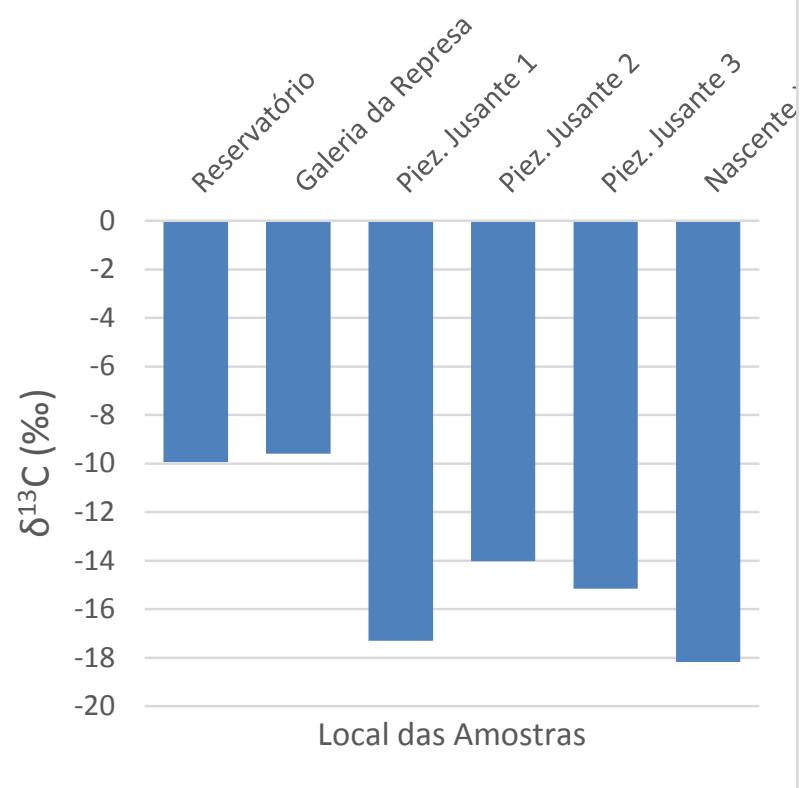

Figura 8. Composição de $\delta^{13} \mathrm{C}$ nas águas da represa de Tapacurá, Pernambuco, Brasil. Elaborado a partir de Agudo et al. (2000).

\subsubsection{Isótopos Radioativos Ambientais}

\subsubsection{Trítio}

O trítio presente no meio ambiente é formado constantemente na alta atmosfera. Também foi gerado, principalmente, por testes nucleares realizados nas décadas de 1950 e 1960 (Noble, 2017). O uso do trítio como traçador no estudo de fugas em lagos e reservatórios pode ser similar em muitos casos aos isótopos estáveis (Bedmar e Araguás, 2002). De acordo com Monev (1999), o trítio é um excelente traçador para muitos problemas científicos ligados ao sistema hidrológico, e de acordo com Abiye e Shaduca (2017), este marcador é excepcional para determinação da escala de tempo das misturas e fluxo da água por fazer parte da molécula de água e comportase como ela, além de seu decaimento poder ser facilmente corrigido. Infelizmente, os teores atuais de trítio no Hemisfério Sul não permitem essas diferenciações.

Foi utilizado por Abiye e Shaduca (2017) no estudo da percolação de água em barragem de rejeitos de urânio como um indicador do tempo decorrido pelas águas subterrâneas desde a sua recarga. As águas de diferentes sistemas contêm conteúdo de trítio relacionado ao tempo de residência da água (ou idade da água) representativa de recarga recente. É útil no estudo de processos de fuga de barragens a consideração do fato de que as águas subterrâneas tem atividade de trítio menor do que as águas pluviais, podendo realizar desta forma a distinção entre estas águas.

Al-Gamal (2000) utilizou o trítio ambiental com um traçador natural para esclarecimento das relações entre a água do reservatório na barragem Al-Jumine na Tunísia. Devido a diferenças nas atividades de trítio nas águas subterrâneas e no reservatório, concluiu-se que a água da fuga é uma mistura entre as águas do reservatório e subterrâneas locais.

$\mathrm{Ba}$ et al. (2014) utilizaram o trítio como traçador para a verificação da procedência da recarga que origina a água do vazamento na barragem da estação hidrelétrica de Suzhi, localizada na província de Qinghai na China. Mediante a análise da Figura 9, os autores concluíram que a água do vazamento no ponto $3 \#$ tem atividade de trítio um pouco menor do que as águas do reservatório e as águas meteóricas, indicando que a fuga de água tem origem no reservatório com um tempo de residência relativamente curto. A água do vazamento no ponto $1 \#$ tem concentração de trítio muito menor do que as águas do reservatório e da precipitação, concluindo que esta água tem um tempo de residência mais longo, o que foi confirmado por isótopos estáveis.

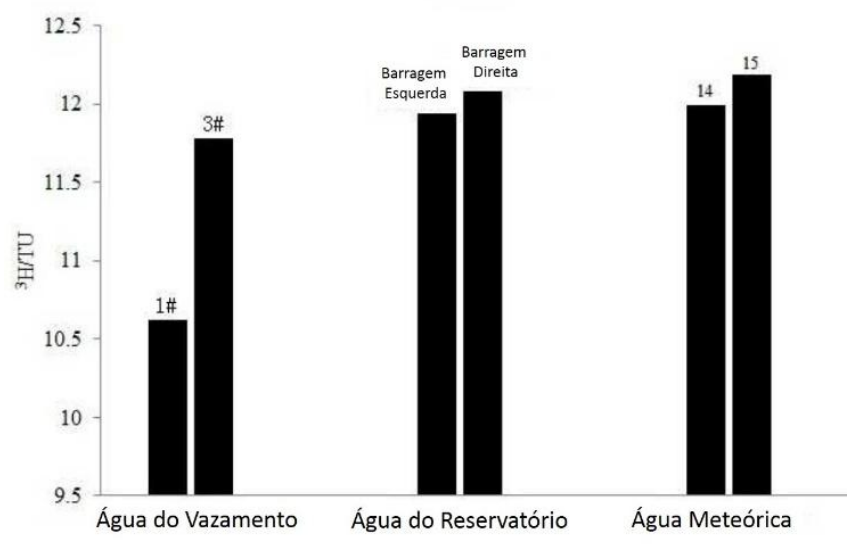

Figura 9. Concentração de trítio ambiental das amostras coletadas na barragem da hidrelétrica de Suzhi na China. Notar semelhança entre águas do reservatório com águas meteóricas e diferença do ponto de vazamento 1 \# com estas águas. Modificado de Ba et al. (2014).

\subsubsection{Radônio-222}

O radônio é um gás nobre gerado em subsuperfície pelo decaimento da família do 
Urânio-238 contido nos minerais. É ótimo traçador ambiental no estudo da interação entre águas subterrâneas e superficiais, pois existem diferenças na concentração deste gás entre águas de aquíferos, lagos e reservatórios e também cursos de água (Grolander, 2009; Da Silva et al., 2009; Clark e Fritz, 1997, DeRubeis, 2013, Pimenta, 2016, Yi et al., 2018).

Devido à característica de identificar interações entre as águas superficiais e subterrâneas, este traçador tem maior potencial de aplicação no reconhecimento de diferentes espécies de água em barragens. As águas no reservatório tiveram quase todo 0 radônio exalado para atmosfera, enquanto que águas do aquífero irão apresentar maiores atividades deste gás.

Yi et al. (2018) utilizaram o ${ }^{222} \mathrm{Rn}$ em conjunto com isótopos do oxigênio, hidrogênio, além dos principais ânions e da temperatura na barragem da hidrelétrica Pushile, na província Liaoning, na China, para estudo sobre a origem da águas de um vazamento. Os resultados apresentados pela análise da atividade do ${ }^{222} R n$ mostraram que as aguas do vazamento têm importante contribuição das águas do reservatório, o que foi confirmado pelos teores de ${ }^{2} \mathrm{H}$ e ${ }^{18} \mathrm{O}$ além dos ânions nitrato, sulfato e cloreto.

Entende-se que há um grande potencial do uso deste gás em estudos de fugas em barragens, há uma escassez de estudos mais detalhado sobre a utilização deste parâmetro, havendo ainda uma breve citação da AEA (2013) para a aplicação deste gás em caso de segurança barramentos.

\subsubsection{Carbono-14}

De acordo com Balderer et al., (1988), a concentração de ${ }^{14} \mathrm{C}$ no carbono dissolvido, tanto o orgânico (COD) ou inorgânico (CID) das águas subterrâneas, é caracterizada pela história geoquímica da água e pelo decaimento radioativo de ${ }^{14} \mathrm{C}$, determinado a partir do tempo de meia vida do mesmo. Se o histórico é conhecido, onde nenhum outro carbono foi adicionado, a sua concentração será mantida constante, a atividade do ${ }^{14} \mathrm{C}$ seria uma função apenas do tempo. Dessa forma, simples atividade pode ser usada para datação da idade das águas subterrâneas, ou seja, o tempo decorrido desde que a água se infiltrou no solo e tornou-se subterrânea.

Devido ao fato do carbono não ser um elemento intrínseco à molécula de água e ter sua função química complexa, são, normalmente, necessárias várias correções nas medições da atividade do ${ }^{14} \mathrm{C}$, para eliminar efeitos de natureza físico-química, geoquímica, biológica, etc., que influenciam os valores detectados na natureza (Clark e Fritz, 1997).

Segundo Bedmar e Araguás (2002), apesar de não ser possível a identificação das águas de reservatórios a partir do ${ }^{14} \mathrm{C}$, visto que as mesmas são recentes, é possível se utilizar da técnica desse traçador em casos onde as águas subterrâneas antigas podem ser encontradas no local da barragem devido à descarga de um aquífero local. Em situações como essa, a água antiga, que estava sendo descarregada ao longo do rio antes da construção da barragem, pode ser desviada para - local da barragem devido à barreira hidráulica formada pela água do reservatório, e dessa maneira, as antigas águas subterrâneas são forçadas a sair à jusante da barragem ou a fluir através dos pontos de fuga na área. Este foi o caso encontrado pelos autores nos reservatórios Giribaile e Bellús, na Espanha. Em ambos os casos, nascentes de água existiam em pontos próximos à barragem. A mesma água foi identificada em alguns furos dentro das galerias das barragens. As medidas de ${ }^{14} \mathrm{C}$ realizadas demonstraram que as águas emergentes tinham vários milhares de anos.

\subsection{Traçadores Intencionais}

São aquelas substâncias injetadas no meio hidrogeológico com o propósito de estudar o fluxo das águas subterrâneas. Estes traçadores podem ser isótopos radioativos, corantes fluorescentes, sais, produtos ativáveis, compostos quelantes e também organismos biológicos (Davis et al., 1980; Käss,1998; Schudel et al., 2002; Leibundgut et al., 2009; Pimenta, 2016).

$\begin{array}{ccc}\text { Os } & \text { traçadores intencionais devem } \\ \text { apresentar } & \text { algumas } & \text { características que }\end{array}$ possibilitem a melhor aplicação da técnica. Algumas dessas propriedades são: os traçadores devem ser inertes, ou seja, não devem interagir com a fração sólida do solo ou reagirem com outras substancias; os traçadores devem ser atóxicos para o ser humano, animais, vegetais e 
microrganismos, evitando possíveis contaminações em longo prazo; os traçadores devem ter baixo custo de aquisição e fácil manuseio; os traçadores devem permitir o uso em concentrações mais elevadas das concentrações dos mesmos constituintes naturalmente encontrados no meio estudado; os traçadores devem ser solúveis em água, além de se comportarem identicamente à água do sistema pesquisado; por fim os traçadores devem ter baixo limite de detecção, possibilitando que uma pequena fração de seja capaz de marcar grandes volumes de água. (Davis et al., 1985; Käss,1998; Schudel et al., 2002; Pimenta, 2016). Salienta-se que não existem traçadores que atendam todos os requisitos citados, mas as características de cada traçador devem ser consideradas durante a escolha e planejamento dos testes a serem realizados, dependendo dos objetivos do estudo e das características físicas do meio.

\subsubsection{Corantes Fluorescentes}

São substâncias orgânicas que emitem fluorescência quando excitadas em determinado comprimento de onda. Podem ser detectadas por fluorímetros in situ e são largamente utilizadas em todo o mundo como traçadores em estudos hidrológicos (Pimenta, 2016).

Sardinha e Mazzutti (2003) e Battaglia et al., (2016) utilizaram os corantes fluorescentes para localizar zonas de infiltrações indesejadas em barragens para a caracterização do maciço, implantação e melhoria de cortina impermeabilizante de cimento.

Ünal et al. (2008) utilizaram traçadores fluorescentes aliado à hidroquímica, testes pinhole e Difratometria de Raios-X para verificar a procedência de argilas que aparecem juntamente com a água de jusante da barragem Armağan na Turquia. Os resultados sugeriram que as argilas são provenientes do preenchimento das descontinuidades presentes nos metacalcários presentes na fundação, havendo a necessidade de cimentação dos locais de fuga do preenchimento argiloso.

Os traçadores fluorescentes mais comuns são a Amidorodamina G, Fluoresceína (também conhecida como Uranina), Eosina, Piranina, Sulforodamina B, Rodamina WT, Rodamina B e Tinopal CBS-X. Estes traçadores podem ter a fluorescência reduzida devido à degradação causada pela presença de luz solar e acidez na água, e também podem ser adsorvidas por material de origem orgânica, diminuindo desta forma a sua detecção e restringindo sua aplicação (Aley, 2002 in Pimenta, 2016).

Al-Gamal (2000) realizou testes com traçadores fluorescentes aliados a isótopos ambientais, além de dados de piezômetros e drenos para determinar a possiblidade e a extensão de vazamento da barragem Al-Jumine na Tunísia, e sua interação com as águas subterrâneas a diferentes distancias do local da barragem. Foi demostrado que há vazamentos na barragem e que estas águas se misturam com a água subterrânea de maior salinidade, e que o vazamento propicia um risco potencial que ameaça a integridade da barragem.

Swaisgood et al. (2005), utilizaram três diferentes corantes fluorescentes para localizar a fonte do vazamento na barragem River Reservoir nas cabeceiras do rio Little Colorado, estado do Arizona, E.U.A.. Foi injetada a Rodamina na porção central da barragem, a eosina foi introduzida na porção à esquerda e a Floresceína foi injetada na porção à direita do ponto central. Em menos de 10 minutos após a injeção dos traçadores, a Rodamina foi detectada à jusante, confirmando os indícios de um sério problema de fuga de água na porção central da barragem.

Lee et al. (2007) realizaram testes com traçadores utilizando Rodamina WT e o íon Brometo para determinar possíveis padrões de infiltração e áreas potenciais de danos na barragem devido ao aparecimento de sinais de erosão interna. À partir das concentrações medidas, foi analisada a curva de chegada (breakthough) e assim inferidos os padrões de infiltração mais prováveis e o potencial dano à área da barragem. Amirhosseini (2011) apresentou estudo utilizando traçadores fluorescentes e ambientais na investigação da interação entre águas superficiais e águas subterrâneas para desta forma orientar o tratamento do vazamento de água da barragem de Havassan, no Iran.

\subsubsection{Isótopos Radioativos}

Os Isótopos Radioativos (também denominados radioisótopos) traçadores devem ter características que permitam acompanhar a dinâmica do sistema sem reagir quimicamente 
com o meio ou ficar adsorvido no caminho, razão pela qual em muitos casos se deve utilizar mais de um traçador simultaneamente. Os traçadores radioativos emissores gama tem a vantagem de permitirem detecções diretas em campo e tem a de extinguir-se com o tempo, exceto pelo trítio que é emissor beta e sua determinação é realizada em laboratório. Segundo Pimenta (2016), isótopos radioativos tem a desvantagem de necessitarem de um Plano de Proteção Radiológica e de autorização para aquisição, transporte e manipulação junto a organismos reguladores, que no caso do Brasil a responsável por estes procedimentos é a Comissão Nacional de Energia Nuclear (CNEN).

\subsubsection{Trítio}

$\mathrm{O} 3 \mathrm{H}$ artificial pode ser injetado em locais com suspeitas de vazamento a jusante da barragem para conferir obter a trajetória da água e mensurar a quantidade de vazamento. Rojas et al. (2004) e Valencia et al. (2011) realizaram estudos para medir a hidrodinâmica das infiltrações surgidas próxima a barragens de rejeitos de mineração no Peru. A Figura 10 apresenta os picos de chegada da nuvem de trítio que percolou pela geomembrana e foi detectada na saída do dreno de fundo da barragem de rejeitos (Valencia et al., 2011).

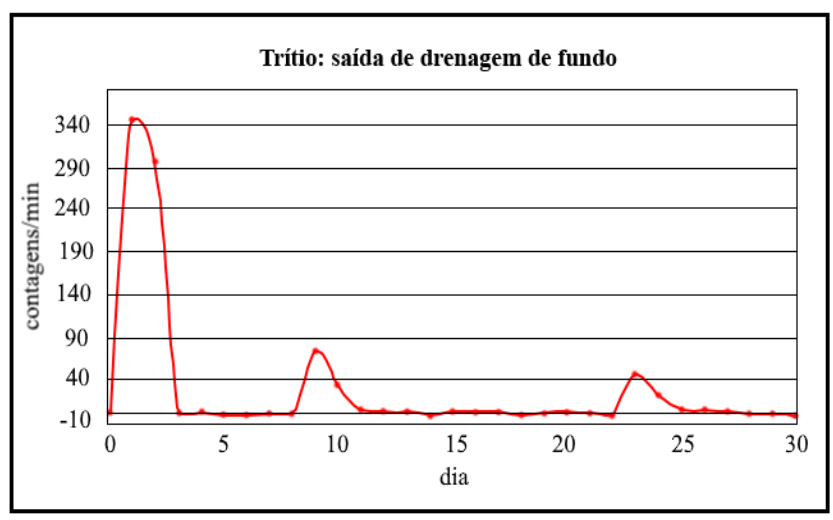

Figura 10. Resultados da atividade de trítio no dreno de fundo da barragem de rejeitos. Modificado de Valencia et al. (2011).

\subsubsection{2 lodo-131}

Gómez et al. (1975) utilizaram o radiotraçador ${ }^{131} \mathrm{I}$ na forma de iodeto de sódio (Nal) para se medir a velocidade de percolação da água pelo dique Sumampa, na Argentina, e verificar se a permeabilidade real está ajustada com os valores projetados. A pesquisa destes autores concluiu que a velocidade da água no maciço da barragem está de acordo com os valores de referência da literatura e com os valores de projeto.

Com objetivo de mensurar a dimensão de infiltração e identificar possíveis zonas de anomalias na barragem Tri $\mathrm{Na}$, na região sul do Vietnã, Hien e Khoi (1996) utilizaram da técnica de radioisótopos traçadores. Foi empregado no estudo ${ }^{131}$ I em solução de iodeto de sódio para possibilitar o cálculo da permeabilidade da barragem e assim, comparar esse valor com o adquirido anteriormente ao início do projeto, por meio de pesquisas hidrogeológicas. Observaramse valores de permeabilidade na ordem de uma a duas vezes maiores do que o esperado, o que indica a presença de infiltração no corpo da barragem após o represamento da água no reservatório. $O$ processo de infiltração ao longo dos anos gerou o fenômeno de erosão interna que, por sua vez, provocou um aumento de poros internos. Entretanto, não foram observados zonas de vazamentos.

No Brasil foi produzida uma pesquisa pelo Instituto de Pesquisas Energéticas e Nucleares (IPEN), São Paulo (Sanchez et al.,1975), com a finalidade de estudar a infiltração de água na barragem de Ilha Solteira, estabelecida no rio Paraná. Para isso o radioisótopo ${ }^{131}$ I foi usado, tendo como justificativas que já havia um estudo anterior utilizando o radioisótopo ${ }^{82} \mathrm{Br}$, e também o fato de que por possuir uma meia vida de 8,05 dias permitiria estender o experimento por um tempo maior que 30 dias e por permitir uma produção simples do isótopo. Foram aplicadas duas técnicas no estudo, uma que mensurou o tempo de chegada do traçador nos poços de bombeamento, sabendo-se se a distância entre os poços e o furo onde foi feita a injeção; e outra que, ao ocorrer uma redução da concentração do ${ }^{131}$ I, devido ao escoamento da água, foi possível determinar a velocidade de trânsito da água. Desse modo, os resultados dos ensaios obtidos indicaram a presença de descontinuidades geotécnicas formadas pelo contato entre derrames basálticos que passam na região do furo de injeção e seguem até os poços situados na margem esquerda do rio Paraná, à jusante da barragem.

\subsubsection{Ouro-198}

O ${ }^{198} \mathrm{Au}$ é radioisótopo artificial que é 
muito reativo com o solo, sendo fortemente absorvidos pelos materiais sólidos, e por isso, é utilizado unicamente para identificar os locais exatos onde ocorre a água é infiltrada. Dessa forma, é possível usar desse traçador para localizar os pontos de entrada de água nas barragens, sugerem Bedmar e Araguás (2002).

No estudo realizado por Wibagiyo et al. (1998), na barragem de Ngancar, estabelecida a aproximadamente $15 \mathrm{~km}$ a leste da cidade de Baturetno, Wonogiri, foi aplicado traçador ${ }^{198} \mathrm{Au}$, na forma de ${ }^{198} \mathrm{AuCl}_{3}$ (Cloreto de ouro) para examinar vazamentos que poderiam estar ocorrendo na base do dique. O Cloreto de ouro por ser solúvel em água, ao ser injetado na água do reservatório, foi transportado pelo fluxo de água que seguem os canais de vazamento. Alguns dos traçadores foram absorvidos ao solo na parte inferior da barragem, especialmente ao redor dos canais de vazamento, e foram detectados por seus diferentes níveis de radiações. Foi elaborada uma enumeração desses níveis e assim, tornou-se possível a obtenção de um mapeamento com as linhas de contorno que ligam os mesmos valores de radiação por meio de interpolação. A partir da análise dos mapas de contorno de radiação tendo como base o padrão de dispersão dos traçadores, conclui-se que a área à direita do pé da barragem ocorre infiltração, ao contrário da área a esquerda do pé da barragem.

O traçador ${ }^{198} \mathrm{Au}$ foi aplicado na barragem de Pedu, no estado de Kedah, Malásia, em pesquisa feita por Easey e Hanna (1984), para rastrear os locais de infiltração. Em conjunto com o ${ }^{198} \mathrm{Au}$ na forma de HCIAu (Ácido auriclorídrico), também foi usado o trítio na forma de água tritiada, sendo que o segundo seria para evidenciar a ligação entre os pontos em que a água estaria se infiltrando e as nascentes no entorno da barragem. Foi fabricado um dispositivo de injeção submerso para possibilitar a inserção dos traçadores a uma altura constante de $5 \mathrm{~m}$ acima da geomembrana, e com base nos dados medidos, foram feitos os mapas a partir da qual áreas potenciais de infiltração foram identificadas. Verificou-se neste estudo que a infiltração indesejada estava ocorrendo no lado norte da barragem.

Ibarra et al. (1979) também utilizaram do Ácido auriclorídrico marcado com ${ }^{198} \mathrm{Au}$ para estudar as condições da barragem Las Lajas, local no México, a fim de identificar possíveis vazamentos de água. $\mathrm{O}{ }^{198} \mathrm{Au}$ foi escolhido para esse estudo, principalmente, por sua característica de traçador não conservativo, ficando parte retido pelas partículas sólidas do solo; ter uma meia-vida curta, o que favorece a realização de um maior número de testes; e devido a sua maior energia de radiação gama, tornando sua detecção mais eficiente. Ele foi obtido em um reator nuclear, onde foi realizada a sua ativação por intermédio de um feixe de nêutrons incidindo sobre uma folha de ouro. O sistema de detecção da radiação emitida pelo ${ }^{198} \mathrm{Au}$, nesse estudo, foi formado por três detectores conectados a três medidores com gráficos associados, sendo eles posicionados em um tubo fixado na popa de um barco, atingindo uma profundidade máxima de $15 \mathrm{~m}$. Os dados obtidos no campo foram processados para obter os mapas contendo as curvas de concentrações do traçador por diferentes tempos que mostram o movimento do ${ }^{198} \mathrm{Au}$. Foram identificadas diversas zonas de vazamento de água, sendo as principais, as encontradas na ombreira direita da barragem, por possuírem os maiores vazões de fluxo.

\subsubsection{Bromo-82}

lya et al. (1967), realizaram um estudo na barragem de Srisailam, localizada na Índia, onde foi utilizado o ${ }^{82} \mathrm{Br}$ na forma química de brometo de potássio a fim de detectar os reais caminhos de fluxos de infiltração, visto que já tinha se observado a ocorrência de vazamentos no reservatório. $\mathrm{O}{ }^{82} \mathrm{Br}$ foi escolhido como traçador a ser utilizado por possuir propriedades adequadas para o propósito do estudo: possui alta energia gama emitida; alta solubilidade em água; não ser muito absorvido pelo solo; e por apresentar alta eficiência de detecção da sua radiação gama. Além disso, sua meia vida é muito curta e por isso, limita-se seu uso a casos de vazamento muito ativos já localizados. Dessa forma, foi possível apontar os pontos de entrada e saída da água, e as linhas de fluxo de infiltração. Ao realizar as observações in situ do traçador, após as injeções, obteve-se como resultado que o movimento de infiltração de água na barragem está localizado no lado esquerdo da mesma.

\subsubsection{Sais (Traçadores lônicos)}

Os sais são traçadores intencionais que, ao serem dissolvidos em água, ficam eletricamente atraídos e formam os pares iônicos. Eles se relacionam diretamente com a 
condutividade elétrica da solução, sendo que um aumento da concentração iônica gera um aumento da condutividade. Sais como os íons cloreto $\left(\mathrm{Cl}^{-}\right)$e brometo $\left(\mathrm{Br}^{-}\right)$são os mais utilizados na técnica, porém também podem ser utilizados outros sais em situações específicas (Pimenta, 2016).

De acordo com Contreras e Hérnandez (2010), o íon cloreto tem a vantagem de ser facilmente encontrado na forma de $\mathrm{NaCl}$ (sal de cozinha) e de possuir um comportamento próximo ao ideal ao que se espera de um traçador intencional. Além disso, ele pode ser injetado em qualquer massa de água. A principal limitação deste traçador diz a respeito do fato de que necessita de enormes quantidades de injeção, que inclusive podem acarretar correntes de densidade iniciais. Como $0{ }^{82} \mathrm{Br}$, são usados quando o local do vazamento já foi identificado.

Como apresentado anteriormente, é possível relacionar a concentração dos traçadores salinos injetados com a condutividade elétrica da água. Uma forma de fazer essa relação é através da técnica de Potencial Espontâneo (SP), um método geofísico de investigação.

A técnica de SP tem sido utilizada por diferentes autores há várias décadas para o estudo de vazamentos em barragens, visto que esta técnica visa localizar os fluxos de águas subterrâneas mediante a medição dos diferentes potenciais elétricos gerados nas superfícies. O método se baseia no fato de que a água subterrânea ao ser escoada pelos diversos condutos do solo pode gerar diferenças de potencial, sendo resultado de uma interação entre a água e o material sólido. Essas diferenças são proporcionais à velocidade e a vazão do fluxo da água, fazendo o potencial elétrico aumentar ao longo da direção do fluxo (Bedmar e Araguás, 2002).

Ao injetar um traçador salino a montante de uma barragem é possível alterar a condutividade elétrica da solução, tendo como consequência a diminuição dos sinais do potencial elétrico que estão relacionados com o fluxo da água. A variação desse sinal pode ser medida a partir dos eletrodos presentes na superfície, tendo como o esperado uma variação positiva em relação ao estado inicial antes da injeção do traçador salino. Com este método é possível localizar o fluxo de água do interior da barragem, determinando o caminho preferencial, por meio da variação, no espaço e no tempo, dos sinais de potencial resultantes do transporte da água subterrânea que contém o sal (Bolève et al., 2011).

Em estudo realizado no sul da França por Bolève et al. (2011), já com um vazamento comprovado, localizou-se a área onde este se encontrava através de um mapeamento do potencial espontâneo e, quantificou-se a taxa de fluxo de vazamento, com o cálculo da permeabilidade. $O$ vazamento se encontrava no ângulo sul do reservatório, e devido à presença de fendas foi possível notar, a partir do mapeamento do SP, uma redução significativa do sinal de potencial eléctrico, resultado condizente com o esperado de fugas de barragem. Realizaram-se duas injeções de traçadores salinos e foi possível notar dois picos anômalos com variação positiva do sinal (Figura 11). Por fim, a partir da diferença de tempo entre as injeções de solução salina e a ocorrência do pico, além da distância entre a injeção e os elétrodos, foi feita uma estimativa da permeabilidade, obtendo um valor de $(10 \pm 5) \mathrm{x}$ $1010 \mathrm{~m}^{2}$.

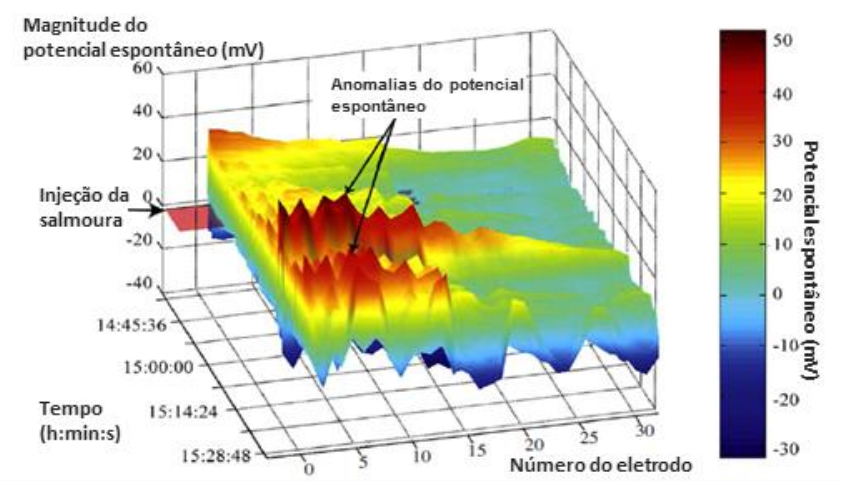

Figura 11. Variação temporal dos dados de potencial na crista da barragem. Os dois picos positivos estão relacionados com a injeção do sal, aparecendo nos eletrodos 1 a 16. Modificado de Bolève et al.(2011).

\subsection{Técnicas de Investigação}

Existem várias técnicas de investigação das fugas em barragens, e os traçadores representam um método direto e confirmatório, e os seus resultados não podem ser alcançados por outros métodos (Käss, 1998).

O primeiro passo para estes estudos é a
obtenção de informações geológicas,
geotécnicas e hidrogeológicas da área de estudo
(Deshpande e Panvalkar, 2018). Estas
informações básicas irão guiar o estabelecimento
das hipóteses iniciais de investigação.


Os estudos devem combinar o uso de diversas técnicas (Bedmar e Araguás, 2002), como investigações geológico-geotécnicas, inspeções visuais, instrumentação na barragem, levantamentos geofísicos terrestres (métodos elétricos), perfilagem de poços, monitoramentos topográficos, hidrometria, modelagem matemática, etc.

Nos estudos utilizando traçadores ambientais devem ser realizadas campanhas de amostragens de água para análise laboratorial nos pontos mais importantes, como águas do reservatório, poços e piezômetros, surgências, e outros pontos de água disponíveis. Também é indicada a análise de águas pluviais do local. Durante estas campanhas devem ser medidos in situ os parâmetros físico-químicos $\mathrm{pH}$, Condutividade Elétrica, Eh, Temperatura, Turbidez, usando medidores multi-parâmetros ou outros específicos para cada medição.

De acordo com o manual da FEMA (2015), os testes com traçadores intencionais podem ser utilizados na investigação dos padrões de fuga na fundação, ombreiras ou no próprio maciço da barragem. Estes testes têm como proposta inicial a confirmação da existência de conexões hidráulicas entre o ponto de injeção e o de detecção, e desta forma, sabendo-se a distância entre estes dois pontos, tem-se a velocidade do fluxo entre estes pontos.

Os estudos realizados por Pimenta e Moreira (2018) na mina abandonada Engenho D’água, localizada em Rio Acima, Minas Gerais, Brasil, utilizaram dessas diversas técnicas de investigação, a fim de caracterizar o local de estudo e compreender o escoamento que vem ocorrendo nas geomembranas e processos de percolação da água contaminada nas barragens de rejeitos. Realizados pelo Centro de Desenvolvimento da Tecnologia Nuclear (CDTN), foi realizada preliminarmente caracterização geológica e geotécnica, usando dados secundários acrescentados com informações recolhidas no campo, auxiliando nas etapas de investigação com traçadores ambientais hidroquímicos.

Nasseh et al. (2013) enfatizam a importância do planejamento dos pontos de injeção e amostragem em todos os projetos envolvendo uso de traçadores. Os traçadores podem ser injetados em furos de sonda, poços de monitoramento, ou em locais específicos dentro do reservatório (Figura 12). A fuga de água é detectada à jusante da barragem em poços, surgências e em cursos d'água com o uso de equipamentos de detecção apropriados para cada tipo de traçador. Na figura 12, em ' $A$ ', o traçador é injetado na superfície do reservatório e amostrado nos poços localizados na barragem e à jusante. Já em "B" o traçador é injetado em um poço localizado sobre a barragem e detectado nos pontos de amostragem à jusante. $E$ em "C" o traçador é injetado no fundo do reservatório próximo do pé de montante e é detectado à jusante da barragem.

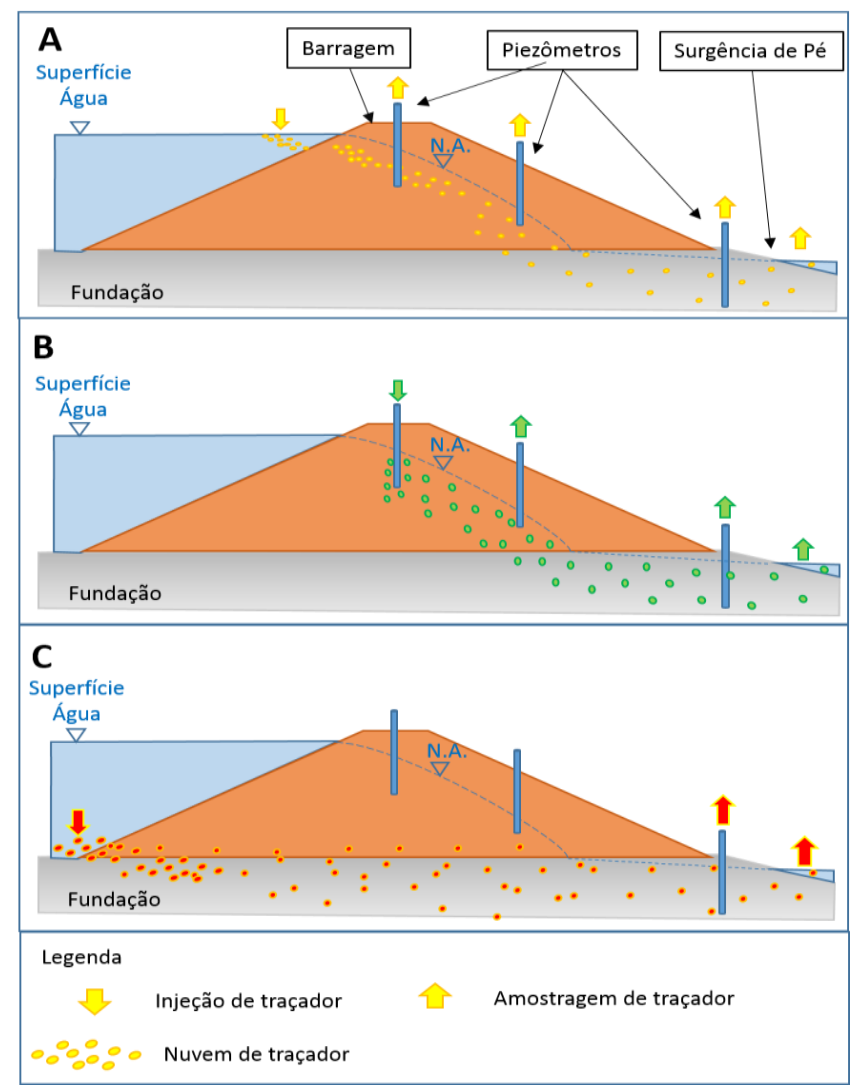

Figura 12. Alguns tipos de teste com traçadores em barragens de terra.

Os testes de fluxo horizontal e vertical em poço único (em inglês, single well test) também são bastante utilizados, havendo vários estudos de caso compilados por Bedmar e Araguás (2002). Trata-se da marcação da coluna de água do poço por um traçador por uma mangueira e posterior execução de perfilagens para medição da concentração do traçador pela coluna de água do poço (Figura 13). A comparação entre os diversos perfis de concentração no decorrer do tempo, indicam zonas de entrada e saída de água do poço, sendo possível também a determinação da velocidade da água nestes trechos por meio de cálculos matemáticos, como apresentado por Pimenta, (2016); Bedmar e 
Araguás (2002), e por Jiansheng e Haizhou (2001) que realizaram o teste em poço único na ombreira esquerda da barragem de Liujiaxia na China.

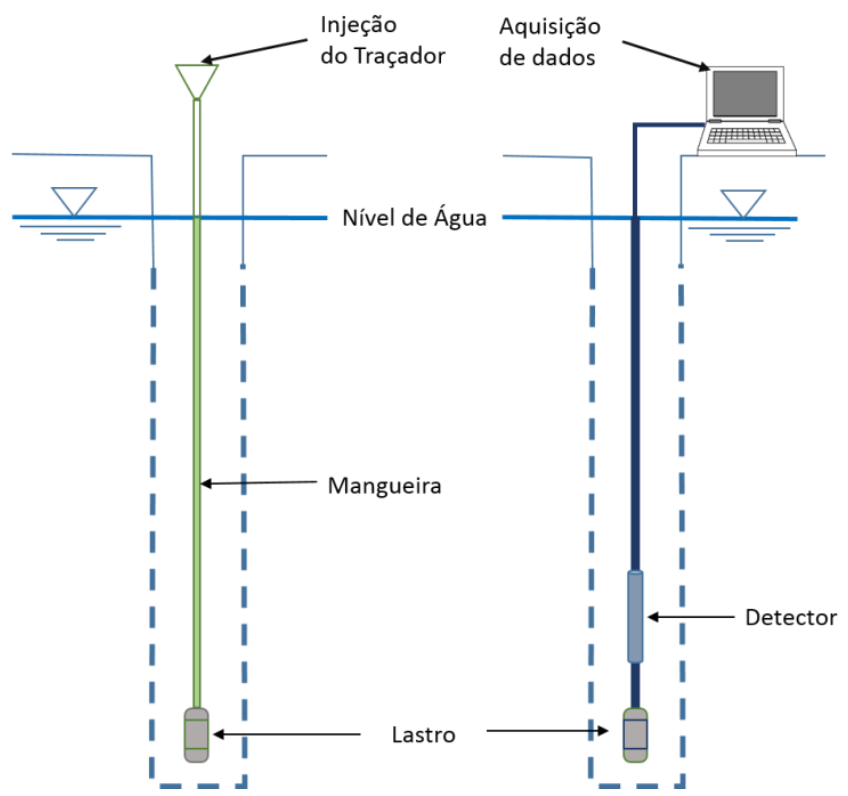

Figura 13. Marcação da coluna de água do poço utilizando mangueira para inserir o traçador e detecção da concentração de traçador através de perfilagens em sucessivos intervalos de tempo.

Noble et al. (2017) realizou estudos utilizando traçadores ambientais, (parâmetros físico-quimicos, análise química e os isótopos ambientais, ${ }^{2} \mathrm{H},{ }^{18} \mathrm{O},{ }^{3} \mathrm{H}$ ) em conjunto com dados de medições hidrométricas (níveis de água, vazões) para verificar a procedência da água de surgência no pé da ombreira esquerda da barragem de terra Gollaleru, na Índia. Estes autores concluíram que a água da surgência é proveniente do reservatório em mistura com a água subterrânea local.

No estudo sobre a infiltração de águas contaminadas de uma barragem de rejeitos de mina de urânio na Namíbia, Abiye e Shaduka (2017) realizaram estudos envolvendo a análise hidroquímica (C.E., pH, O.R.P. e temperatura), isótopos estáveis $\left({ }^{2} \mathrm{H}\right.$ e $\left.{ }^{18} \mathrm{O}\right)$ e o trítio ambiental. Foram registradas águas com $\mathrm{pH}$ alcalino e alta condutividade elétrica (comparada com águas não poluídas). Neste caso, os parâmetros físicoquímicos funcionaram com traçadores das águas poluídas por urânio provenientes da barragem de rejeitos.

Estudo envolvendo os traçadores ambientais integrados com intencionais foi realizado no trabalho de Zhongcheng et al.
(2009). Estes discutiram os princípios de uma abordagem conjunta entre vários traçadores usados na detecção de fugas utilizando os traçadores deutério, ${ }^{18} \mathrm{O}$, trítio $\mathrm{e}^{131} \mid$ combinados com parâmetros físico-químicos medidos in situ como Condutividade Elétrica (C.E.), Temperatura (T), $\mathrm{Ca}^{2+}, \mathrm{Cl}^{-}$, Sólidos Totais Dissolvidos (S.T.D.). Hocini e Mami (2011) combinaram o uso de diversos traçadores para investigar a infiltração de barragem Beni-Haroun na Algeria. Alikaj et al. (2016) realizaram estudo na barragem de Komani na Albânia, envolvendo uma investigação geofísica em conjunto com análise hidroquímica e de isótopos estáveis para determinar a infiltração que ocorre na barragem.

\subsection{Remediação}

Peng e Wang (2008) destacam que a ignorância sobre os processos existentes em vazamento indesejados em barragem pode resultar em desastres de danos imprevisíveis, e estes sugerem que sejam tomadas as medidas remediadoras.

Jiansheng e Haizhou (2001) destacam a importância do método dos traçadores como ferramenta na investigação de vazamentos em barragens, e enfatizam que estas investigações são necessárias para se ter um conhecimento prévio antes de serem tomadas as medidas corretivas necessárias.

Para Noble et al. (2017), as atividades de remediação são de alto custo para as companhias gestoras, e podem ser executadas sem o devido conhecimento sobre a natureza dos fenômenos envolvidos no processo de fuga de água. Deshpande e Panvalkar (2018) indicam que para garantir a segurança de uma barragem se faz essencial à identificação com o máximo de precisão as possíveis áreas de perda de água e os pontos de entrada nas estruturas condutoras de água.

Com base nos resultados obtidos por testes com traçadores fluorescentes, Turkmen (2003) pôde realizar a cimentação em locais de maior velocidade das águas subterrâneas, e também comparar as velocidades após o processo de impermeabilização com injeção de cimento (grouting) em barragem na Turquia.

A Tabela 1 apresenta uma comparação entre as velocidades medidas com corantes fluorescentes após as operações de injeção de cimento para implantação de cortina 
impermeabilizante (Turkmen, 2003).

Tabela 1. Velocidades da água subterrânea determinadas utilizando traçadores fluorescentes após as operações de cimentação (grouting) em barragem na Turquia. Modificado de Turkmen (2003).

\begin{tabular}{c|c|c}
\hline $\begin{array}{c}\text { Locais de } \\
\text { observação }\end{array}$ & $\begin{array}{c}\text { Velocidade } \\
\text { após a } \\
\text { construção } \\
\text { da cortina de } \\
\text { cimento em } \\
\mathbf{1 9 8 8}(\mathbf{m} / \mathbf{h})\end{array}$ & $\begin{array}{c}\text { Velocidade } \\
\text { após a } \\
\text { segunda } \\
\text { cimentação } \\
\text { em } \mathbf{1 9 9 0} \\
\mathbf{( m / h )}\end{array}$ \\
\hline $\mathrm{K}-1$ & 6 & 4,5 \\
$\mathrm{~K}-2$ & 6 & 4,5 \\
$\mathrm{~K}-3$ & 5,5 & 3,6 \\
\hline
\end{tabular}

Dentro desta perspectiva de testar a eficiência da cortina impermeabilizante (grount courtain) na barragem de Bidvaz no Iran, Nasseh et al. (2013) utilizou os corantes fluorescentes Rodamina B e Fluoresceína como traçadores. A Rodamina $B$ foi detectada no ponto de surgência no pé da barragem, confirmando a conexão hidráulica entre os dois pontos e calculada uma velocidade de $28,6 \mathrm{~m} / \mathrm{h}$ e indicando um fluxo subterrâneo turbulento ao longo das rochas calcárias presentes na ombreira esquerda da barragem, apontando para a ineficiência da cortina impermeabilizante naquela porção. A Fluoresceína não foi detectada entre o ponto de amostragem e de detecção, demonstrando a eficiência da cortina impermeabilizante naquela porção. Mediante a estes testes o autor sugere que a cortina impermeabilizante seja prolongada até a porção onde foram detectados os vazamentos.

\subsection{Técnicas Complementares}

No estudo utilizando traçadores, Noble et al. (2017) enfatizam a necessidade de uso de técnicas multidisciplinares na investigação dos vazamentos em barragens. (a) Hidrometria, (b) Métodos Geofísicos, (c) Traçadores Ambientais; (d) Traçadores Intencionais; e (e) Modelamento Numérico.

Nas investigações sobre a hidroquímica das infiltrações, Craft (2005) recomenda a interdisciplinaridade e a integração de informações de diversos campos, como a química analítica, geoquímica, hidrologia, geofísica, engenharia civil e geotécnica.

Petitta et al. (2010) utilizaram isótopos estáveis da água para a confirmação do modelo conceitual concebido a partir de dados levantados de piezometria, medições de descarga, testes de bombeamento e de análises químicas realizados em uma barragem formada por um fluxo de detritos após o escorregamento de talude. A assinatura isotópica da água confirmou com exatidão os resultados no modelo conceitual de fluxo, estabelecendo a interação entre as águas superficiais e subterrâneas por meio da barragem de escorregamento.

\subsubsection{Geofísica}

Além da utilização do Potencial Espontaneo (SP) em conjunto com a injeção de traçador salino (Bolève et al., 2011) citado no ítem 4.2.3, outros métodos geofísicos merecem destaque, principalmente a perfilagem geofísica e a Tomografia por Resistividade.

A perfilagem geofísica em poços foi utilizada por Deschpande e Panvalkar (2018) em conjunto com traçadores nas barragens de Pune e Bhama-Askhed, na Índia. Estes autores mencionam a perfilagem geofísica como uma ferramenta que vem sendo cada vez mais utilizada no mundo para delimitação de zonas de maior permeabilidade. Esta técnica apresenta um baixo custo na identificação de zonas susceptíveis de infiltração, e atua como um complemento às demais técnicas de verificação. Os perfis podem ser executados furos de sondagem e poços, mesmo aqueles revestidos por tubos de metal ou plástico. Os logs dos poços podem ser interpretados para a determinação da litologia, resistividade, densidade, porosidades, teor de umidade entre outros. A Tabela 2 apresenta os métodos de perfilagem geofísica e os parâmetros medidos por cada método. 
Tabela 2. Métodos na perfilagem de poços

(Extraído de Deschpande e Panvalkar, 2018).

\begin{tabular}{c|c}
\hline $\begin{array}{c}\text { Método da } \\
\text { Perfilagem }\end{array}$ & Parâmetros Medidos \\
\hline Resistividade & Resistividade Elétrica \\
Polarização Espontânea & Potencial Elétrico \\
Raio Gama Natural & Radiação Gama Natural \\
Raio Gama-Gama & Densidade Aparente \\
Neurônico & Porosidade \\
Sônico & Propriedades Mecânicas \\
Temperatura & Temperatura do Fluido \\
Caliper & Diâmetro do Furo \\
\hline
\end{tabular}

A tomografia por Resistividade foi utilizada por Zhao et al. (2011) em modelos reduzidos de barragens como comparação e confirmação dos resultados de testes com traçadores. Estes autores concluíram que o método da tomografia de resistividade tem maior precisão do que o método dos traçadores na identificação dos locais de percolação de água.

\subsubsection{Ferramentas Computacionais}

Os códigos computacionais representam uma ferramenta poderosa na análise e interpretação dos resultados obtidos pelos traçadores ambientais.

\subsubsection{Modelagem de Fluxo}

O software MODFLOW (Hughes et al. 2017; Langevin et al., 2017) foi utilizado por Craft (1992, in Craft, 2005) para o estudo da infiltração na barragem Glen Canyon, Colorado, E.U.A.. Este foi capaz de programar um modelo de fluxo tridimensional da água subterrânea, e revelou no estudo da barragem Glen Canyon que a água da infiltração flui horizontalmente no entorno da barragem, tendo sido considerado um tempo de residência da água estimado de 6 meses. Os diversos traçadores podem ser aplicados de forma a confirmar os resultados obtidos por modelos numéricos de fluxo e transporte de contaminantes, como também para a calibração destes modelos computacionais.

\subsubsection{Modelagem Hidroquímica}

Os diagramas hidroquímicos de Piper, Stiff, entre outros, podem ser feitos pelo software AcquaChem (Waterloo Hydrogeologic, 2017), ou o software livre brasileiro Qualigraf (Möbus, 2014).

O software NETPATH (Plummer, et al., 1994) pode ser utilizado para auxiliar na verificação no caso das características hidroquímicas da infiltração serem o resultado da mistura da água do reservatório com a água do aquífero local (Craft, 2005).

Craft (2005) cita como ferramenta essencial na interpretação hidrogeoquímica dos dados químicos do vazamento os programas computacionais como WATEQ4F, MINTEQA2 e o PHREEQE. Estes softwares são utilizados para realização do cálculo dos Índices de Saturação Mineral (ISM) para cada amostra coletada. Estes códigos são utilizados para a modelagem hidroquímica usando métodos numéricos baseados nas concentrações medidas nas amostras e nos banco de dados das possíveis reações químicas esperadas que ocorram nas águas. Um dos resultados mais úteis destes modelos na avaliação das infiltrações é o cálculo do ISM para os minerais solúveis mais comuns. Geralmente o ISM é dado na notação "Log (AP/KT)". Quando o ISM é negativo, significa que a água está insaturada dos constituintes deste mineral, havendo a tendência para a dissolução deste. Por outro lado, quando o valor de ISM é positivo, significa que a água está saturada nos constituintes deste mineral e que a tendência é que estes constituintes se precipitem. Estes resultados são importantes para a comparação entre as águas do reservatório e as possíveis águas de infiltração à jusante. Quando o ISM aumenta entre estes pontos, sugere-se que esteja havendo uma possível dissolução de minerais durante o fluxo, ou a mistura com águas mais concentradas. E uma diminuição do ISM entre as águas do reservatório e águas de jusante, sugerem a precipitação de minerais durante o fluxo, ou mesmo a mistura com águas menos concentradas.

Na mina do Engenho D'água, Pimenta e Moreira (2018) realizaram a modelagem hidroquímica com objetivo de entender melhor os processos químicos que ocorrem no interior das barragens de rejeitos. A modelagem foi feita com o uso do software PHREEQC, usando, dando-se maior ênfase ao contaminante arsênio. Essa ferramenta de modelagem mostrou-se eficiente, visto que com ela foi possível notar a existência 
de uma mistura das águas mais concentradas de arsênio com águas subterrâneas naturais contaminadas menos concentradas à jusante do barramento, indicando uma possível fuga de solutos através das geomembranas das barragens.

\subsubsection{Modelagem Estatística}

A análise por métodos estatísticos multivariados como Análise Discriminante, Análise de Agrupamentos, ou por Componentes Principais, são segundo Craft (2005) ferramentas robustas para classificar as amostras de acordo com os múltiplos parâmetros detectados. Podemse utilizar os programas SPPS, SAS, MINITAB entre outros.

Peng e Wang (2008) utilizaram o software SPSS para Windows para realizar uma análise estatística por Regressão Linear Múltipla dos dados levantados. Essa abordagem classificou as variáveis independentes significativas que afetam a variável dependente (drenagem do filtro da barragem). Foi utilizada a Correlação de Coeficientes de Pearson para verificação da relação entre a drenagem nos filtros da barragem com outras variáveis como a precipitação e o nível do reservatório nas diferentes estações do ano.

Pimenta e Moreira (2018) empregaram o a técnica da estatística multivariada utilizado o software MINITAB. A partir da Análise de Grupamentos (clusters) foram definidos grupos com similaridades. Para esta modelagem foram utilizados os parâmetros químicos e físicoquímicos relacionados à campanha de amostragem, tonando-se possível à construção de dendrogramas, para análise dos dados. Os resultados obtidos revelaram grupos de similaridade entre amostras individuais, separando águas não contaminadas das águas contaminadas relativas à barragem $\mathrm{B} 2$, e 0 agrupamento dos traçadores hidroquímicos revelaram similaridades entre o arsénio, o ferro, o manganês e o potencial redox.

\section{CONCLUSÕES}

A utilização de traçadores ambientais e intencionais mostrou ser de grande aplicabilidade no estudo de fugas de barragens e reservatórios. Trabalhos publicados em diversas partes do mundo mostraram resultados que confirmam a eficácia destas técnicas na detecção e parametrização de fugas indesejadas de água em área de barramentos, possibilitando a caracterização do processo de fluxo, e contribuindo para aplicação de ações corretivas nas porções de maior permeabilidade de forma a conter os efeitos danosos do processo de erosão interna.

Estes estudos são de vital importância nas investigações em todos os tipos de barragem, estando dentro das políticas de segurança de barragens, devendo ser inseridos nos procedimentos de investigação de vazamentos, proporcionando desta forma maior conhecimento dos problemas, possibilitando remediações e assegurando maior segurança das estruturas e prevenindo possíveis desastres de rompimentos, que causam perda de vidas humanas, prejuízos materiais e graves impactos ao meio ambiente.

\section{AGRADECIMENTOS}

Agradecimentos à Fundação de Amparo à Pesquisa de Minas Gerais (FAPEMIG), pelo fomento desta pesquisa (Processo no APQ01855-16), ao Centro de Desenvolvimento da Tecnologia Nuclear (CDTN) pela infraestrutura utilizada, à Agência Internacional de Energia Atômica (AIEA) pelo apoio e ao Conselho Nacional de Desenvolvimento Científico e Tecnológico (CNPq) pela concessão de bolsa.

\section{REFERÊNCIAS}

1. Abiye, T.; Shaduka, I. Radioactive Seepage though Groundwater Flow the Uranium Mines, Namibia. Hydrology, 2017.

2. AEA, Atomic Energy Authority. Isotopes in Water and Environmental Management. Isotope Hydrology Section, Sri Lanka, 2013.

3. Al-Gamal, S. A. Sources of Leakages at Al-Jumine Dam, NW Tunis, Tunisia. Acta Mineralogica-Petrographica, Szeged, 2000.

4. Agudo, E. G.; Antonino, A. C. D.; Bandeira, J. V.; Bedmar, A. P.; Lira, C. A. B. O.; Menezes, M. O.; Viana, A.; Villar, $\mathrm{H}$. The detection of leaks from Tapacurá dam, Brazil. $1^{\text {st }}$ Joint World Congress on 
Groundwater, 2000. Disponível em: https://aguassubterraneas.abas.org/asubt erraneas/article/view/24321/16320

5. Alikaj, P.; Beqiraj, A.; Jovani, A.; Karriqi, A. Analysis of Water Leakage in Downstream Dam Toe of Komani Dam. Research Gate, 2016. Disponível em https://www.researchgate.net/publication/ 309133629_analysis_of_water_leakage_i n_downstream_dam_toe_of_komani_dam

6. Amirhosseini, Y. K. Application of Isotope and Dye Tracing Methods in Hydrology (Case Study: Havassan Dam Construction). Isotopes in Hydrology, Marine Ecosystems and Climate Change Studies. Proceedings of an International Symposium, Vol. 2, Monaco, 2011.

7. ANA. Agência Nacional das Águas. Manual do Empreendedor, Vol. V, Guia Para Elaboração de Projetos de Barragens. Brasília, 2015.

8. Ibarra, B. A.; Cruz, L. G., Pena, O. R.; Del Arenal, R.; Isotope investigation of water losses from the Las Lajas dam, Chihuahua, Mexico. Isotope Hygrology, Vienna, IAEA, Vol.1, 125-143, 1979.

9. Appelo, C. A. J.; Postma, D. Geochemistry, Groundwater and Pollution, $2^{\mathrm{a}}$ ed., Amsterdam, Balkema Publishers, 2006.

10. Aufleger, M.; Conrad, M.; Goltz, M.; Perzlmaier, S.; Porras, P. Innovative Dam Monitoring Tools Based on Distributed Temperature Measurement. Jordan Journal of Civil Engineering, Vol. 1, № 1, 29-37, 2007.

11. Ba, J.; Zhan, L.; Zhang, B. Isotope Analysis on the Recharge Source of the Leakage Water Behind the Right Dam of Suzhi Hydroeletric Station. Advanced Materials Research, 2014.

12. Balderer, W.; Frape, S.K.; Fritz, P.; Fonte, J-CH.; Louvat, D.; Michelot, J-L. The isotope geochemistry of carbon in groundwater at Stripa. International Stripa Project; Geochimica et Cosmochimica Acta Vol. 53, 1765-1775, 1988.

13. Battaglia, D.; Birindelli, F.; Rinaldi, M.; Vettraino, E.; Bezzi, A. Fluorescent tracer tests for detection of dam leakages: The case of the Bumbuna dam - Sierra
Leone. Engineering Geology, Vol. 205, 30-39, 2016.

14. Bedmar, A. P.; Araguás, L. A. Detection and Prevention of Leaks from Dams. Balkema Publishers, 2002.

15. Bedmar, A. O.; Araguás, L. A.; Agudo, E. G. Carbon Isotope in Assessing the origin of water in dam leakage problems. IAEASM-361/21P, 1999.

16. Bolève, A.; Fry, J-J.; Janod, F.; Lafon, A.; Revil, A. Localization and quantification of leakages in dams using time-lapse selfpotential measurements associated with salt tracer injection. Journal of Hydrology, Vol. 403, 242-252, 2011.

17. CIGB. Comissão Internacional de Grandes Barragens. As Barragens e as Águas no Mundo. International Commission on Large Dams (ICOLD), 2008.

18. Clark, I.; Fritz, P. Environmental Isotopes in the Hydrogeology, Lewis Pub. New York, 1997.

19. Constantz, J. E.; Niswonger, R. G.; Stewart, A. E. Analysis of Temperature Gradients to Determine Stream Exchanges with Ground Water in Rosenberry, D.O., and LaBaugh, J.W. Field techniques for estimating water fluxes between surface water and ground water. U.S. Geological Survey Techniques and Methods 4-D2, 128, 2008.

20. Contreras, I. A.; Hernández, S. H. Techniques for Prevention and Detection of Leakage in Dams and Reservoirs. Prevention and Detection of Leakage, 2010.

21. Cordero, C.; Plata. A. Estudio de fugas de agua en la presa Arenales, Costa Rica: Aplicaciones de técnicas de trazadores, In Estudio de fugas em embalses, IAEA, Vienna, 1999.

22. Craft, D. Seepage Chemistry Manual, Dam Safety Technology Development Program, Bureau of Reclamation, Technical Service Center, U. S. Department of the Interior, Denver, 2005.

23. Davis, S. N.; Thompson, G. M.; Bentley; H. W.; Stiles, G. Ground-Water Tracers A Short Review, Vol. 18, №.1. Ground 
Water, 1980.

24. Davis, S. N.; Cambell, D. J.; Bentley, H. W.; Flynn, T. J. An Introduction to GroundWater Tracers. National Water Well Association. Department of Hydrology and Water Resources, University of Arizona, 1985.

25. Da Silva, L. L.; Donnici, C. L.; Ayala, J. D.; Freitas, C. H.; Moreira, R. M.; Pinto, A. M. F. Traçadores: $O$ Uso de Agentes Químicos para Estudo Hidrológicos, Ambientais, Petroquímicos e Biológicos, Química Nova, Vol. 32, №. 6, 1576-1585, 2009.

26. Derubeis, E. A. Radon as a Tracer of Groundwater - Surface Water Interation in Martis Valley. Thesis of Master of Science in Geology, California State University, East Bay, 2013.

27. Deshpande, N. V.; Panvalkar, G. A. The Potential of Borehole Geophysical Logging and Tracer Techniques in Dam Seepage Investigations, The Masterbuilder, Chennai, 2018.

28. Dornstädter, J. Leakage detection in dams - State of the art, Društvo Slovenski Nacionalni Komite za Velike Pregrade (Slocold), Karlsruhe, 2013. Disponível em: https://www.masterbuilder.co.in/potentialborehole-geophysical-logging-tracertechniques-dam-seepage-investigations/

29. Dornstädter, J.; Heinemann, B. Temperature as Tracer for In Situ Detection of Internal Erosion. Paris, 2012.

30. Dung, B. D.; Giap, T. V.; Quan, L. T.; Minh, D. A.; Lieu, D. B.; Hung, N. M.; Ky, P. Q. Research on the Use of Environmental Isotopes Technique for Safety Assessment of the Đông Mô Reservoir. Vietnam Atomic Energy Commission, Hanoi (VAEC). The Annual Report for 2006. Disponível em: http://www.iaea.org/inis/collection/NCLColl ectionStore/_Public/39/036/39036739.pdf

31. Easey J. F., Hanna G.L. The use of radioisotope tracers to identify the location of seepage areas in a dam. Proceedings of the Symposium on Isotope Techniques in Water Resources Development, IAEA, Vienna, 1987.
32. Johnson, D. Dam Safety Guidelines Part 4 - Dam Design and Construction. Water Resources Program. Department of Ecology, State of Washington, 1993.

33. Fan, Z.; Wang, J.; Mao, H. Studying Leakage form Left Abutment of Xiaolangdi Hydropower Station Using Tracing Method. Journal of Chemical and Pharmaceutical Research, 2014.

34. FEMA. Federal Emergency Management Agency. Evaluation and Monitoring of Seepage and Internal Erosion, Interagency Committee on Dam Safety (ICODS). Maio, 2015.

35. Ferreira, N. S. A. F. As Pesquisas Denominadas "Estado da Arte". Educação \& Sociedade, № 79, 2002.

36. Ghomshei, M. M.; Allen, D. M.; Hydrochemical and Stable Isotope Assessment of Tailing pond leakage, Nickel Plate Mine, British Columbia. Environmental Geology 39, SpringerVerlag, 2000.

37. Gómez, H. R.; Baró, G. B.; Gillen, R. Determinación de Filtraciones y Permeabilidad en un Embalse de Tierra (Sumampa-Catamarca). Comisión Nacional de Energia Atómica, República Argentina, Buenos Aires, 1975.

38. Hien, P. D.; Khoi, L. V. Application of isotope tracer techniques for assessing the seepage of the hydropower dam at Tri An, South Vietnam. Journal of Radioanalylical and Nuclear Chemistry, Vol. 206, N. 2, 295-303, 1996.

39. Hocini, N.; Mami, M. Detection of Water Leaks in the Beni-Haroun Dam (Algeria) Isotopes in Hydrology, Marine Ecosystems and Climate Change Studies. Proceedings of an International Symposium, Monaco, Vol. 2, 2011.

40. Hughes, J. D.; Langevin, C. D.; Banta, E. R. Documentation for the MODFLOW 6 framework: U. S. Geological Survey Techniques and Methods, book 6, chap. A57, 40, 2017. https://doi.org/10.3133/tm6A57.

41. IAEA. Investigating leaks in Dams and Reservoirs. Informativo IAEA, Vienna, 2001.

https://www.iaea.org/technicalcooperation 
/documents/Factsheets/archive/sheet20.p df

42. Iya, V. K.; Krishnamurthy, K.; Aggarwal, K. S.; Rajagopalan, R. A Radiotracer Study on Flow Path of Seepage in the Coffer Dams at Srisailam. International Journal of Applied Radiation and Isotopes, Vol. 18, 349-357, 1967.

43. Jiansheng, C.; Haizhou, D. Study of fissured-rock seepage flow with isotope tracer method in single borehole. Science in China, Vol. 44, 2001.

44. Johansson, S.; Sjödahl, P. Downstream Seepage Detection using Temperature Measurements and Visual Inspection Monitoring Experiences from Røsvatn Field Test Dam and Large Embankment Dams in Sweden. Oslo, 2004.

45. Käss, W., Tracing Techniques in Geohydrology, Publisher A.A. BALKEMA, Rotterdam, Netherlands, 1998.

46. Langevin, C. D.; Hughes, J. D.; Banta, E. R.; Niswonger, R. G., Panday; Sorab; Provost, A. M. Documentation for the MODFLOW 6 Groundwater Flow Model: U.S. Geological Survey Techniques and Methods, book 6, chap. A55, 197, 2017, https://doi.org/10.3133/tm6A55.

47. Lee, J. Y.; Kim, H. S.; Choi, Y. K.; Kim, J. W.; Cheon, J. Y.; YI, M. J. Sequential tracer tests for determining water seepage paths in a large rockfill dam, Nakdong River basin, Korea, Engineering Geology 89. 300-315, 2007.

48. Leibundgut, C.; Maloszewski, P.; Külls, C. Tracers in Hydrology. Editora WilleyBlackwell, 2009.

49. Maksimovich, N. G.; Khmurchik, V. T.; Demenev, A. D. The Hole of Microorganisms in Elevating the Turbidity of Dam Seepage Water, Power Technology and Engineering, Vol. 50, №. 1, 2016.

50. Möbus, G. Tutorial do Programa Qualigraf. Fundação Cearense de Meteorologia e Recursos Hídricos. Fortaleza, 2014. Disponível em: http://www3.funceme.br/qualigraf/uploads/ documentos/Tutorial\%20do\%20programa \%20QualiGraf.pdf

51. Monev, E. Tritium Transport Dynamics for
Determination of Water's Origin on Seepage Investigations. International Symposium on Isotope Techniques in Water Resources Development and Management. Austria, 1999.

52. Mook, W. G. Introduction. in Environmental Isotopes in the Hydrological Cycle - Principles and Applications. Ed. W. G. Mook - IHP-V / Technical Documents in Hydrology, UNESCO, Paris, № 39, 2000.

53. Nasseh, S.; Ghafoori, M.; Moghaddas, N. $\mathrm{H}$.; Lashkaripour, G. R. Investigation of Seepage Paths in Left Abutment of Bidvaz Dam Using Tracing Technique. International Journal of Emerging Technology and Advanced Engineering. Vol. 3, 2013.

54. Nygren, C. Detection of Sudden Seepage Changes in Embankment Dams. Bachelor's Thesis in Computer Science, Stockholm, 2013.

55. Noble, J.; Ansari, M. D. A. Environmental isotope investigation for the identification of source of springs observed in the hillock on the left flank of Gollaleru Earthen Dam, Andhra Pradesh, India. Journal Earth.System Science, Indian Academy of Sciences, Vol.126, № 5, 2017.

56. Oliveira, J. R. C. Contribuição para a Verificação e Controle da Segurança de Pequenas Barragens de Terra, Dissertação de Mestrado Profissional em Engenharia Geotécnica da UFOP, 2008.

57. Panvalkar, G. A.; Chunade, A. D. Tracing Dam seepage using nuclear logging and tracer techniques - a case study, ISH Journal of Hydraulic Engineering, Taylor \& Francis, 2017.

58. Peng, T. R.; Wang, C. H. Identification of Sources and Causes of Leakage on a Zoned Earth Dam in Northern Taiwan: Hydrological and Isotopic Evidence. Applied Geochemistry 23, 2008.

59. Petitta, M.; Mugnozza, G. S.; Barbieri, M.; Fasani, G. B.; Esposito, C. Hydrodynamic and Isotopic Investigations for Evaluating the Mechanisms and Amount of Groundwater Seepage through a Rockslide Dam. Hydrological Processes 24, 2010. 
60. Plummer, L. N.; Prestemon, E. C.; Parkhust, D. L. An Interactive Code (NETPATH) For Modeling NET Geochemical Reactions Along a Flow PATH Version 2.0, U. S. Geological Survey Water-Resources Investigations Report 94-4169, 1994.

61. Pimenta, R. C. Utilização de Traçadores em Estudos Hidrogeológicos. Dissertação de Mestrado. Centro de Desenvolvimento da Tecnologia Nuclear, Belo Horizonte, 2016.

62. Pimenta, R. C.; Moreira, R. Characterization and Hydrochemical Tracers Analysis in an Abandoned Mine, Minas Gerais State, Brazil. $2^{\text {nd }}$ International Congress Planning for Closure of Mining Operations, Santiago, 2018.

63. Rai, S. P.; Kumar, S.; Kumar, B. Rawat, Y. S. Identification of Source of Leakage in Drainage Gallery of Tehri Dam Using Isotopic Techniques. Hydrology Journal, Vol. 35, 2012.

64. Rojas, R.; Visurraga, R.; Maguiña, J.; Condori, J. Evaluación de filtraciones de depósito de relaves en una mina ubicada en el sur del Perú. Informe Científico Tecnológico. Instituto Peruano de Energía Nuclear, Vol. 4, 106-108, 2004.

65. Sanchez, W.; Guidicini, G.; Silva, R. F. Condições de percolação d'agua na ombreira esquerda da Barragem de Ilha Solteira, rio Paraná, utilizando técnicas radioisotópicas. Instituto de Energia Atômica, № 389, 1975.

66. Santiago, M. F.; Frischkorn, H.; Silva, C. M. S. V. Métodos Isotópicos in Hidrogeologia: Conceitos e Aplicações. Fernando A. C. Feitosa [et al]. - 3르. ed. Rio de Janeiro, CPRM, LABHID, 2008.

67. Sardinha, A. E.; Mazzutti, R. Tratamento das Infiltrações Ocorridas na Barragem de Itá. XXV Seminário Nacional de Grandes Barragens. Comitê Brasileiro de Barragens. Salvador, 2003.

68. Schudel, B.; Biaggi, D.; Dervey, T.; Kozel, R.; Müller, I; Ross, J. H.; Schindler, U. Utilisation des traceurs artificiels em hydrogéologie - Guide pratique . Rapp. OFEG, Sér. Géol. 3. - 2002.
69. Swaisgood, J.; Montgomery, J.; Kofoed, V. Straight to the Source of Seepage. International Water Power \& Dam Construction, 2005. Disponível em http://www.waterpowermagazine.com/fea tures/featurestraight-to-the-source-ofseepage/

70. Turkmen, S. Treatment of the Seepage Problems at the Kalecik Dam (Turkey). Engineering Geology, 2003.

71. Ünal, B.; Çelik, M.; Yıldırım, T. Evaluation of seepage problems of the Armağan Dam, Kırklareli, northwestern Turkey. Bull. Eng. Environ, 2008.

72. Valencia, J.; Mamani, E.; Maghella, G.; Condori, J. Determinación de filtraciones de uma relavera utilizando técnicas isotópicas, La Liberdad. Informe Científico Tecnológico. Instituto Peruano de Energía Nuclear, Vol. 11, 76-78, 2011.

73. Yi, P.; Yang, J.; Wang, Y.; Mugwanezal, V. P.; Chen, L.; Aldahan, A. Detecting the Leakage Source of a Reservoir Using Isotopes, Journal of Environmental Radioactivity, 2018.

74. Waterloo Hydrogeologic, AquaChem 2014.2 Water Quality Analysis \& Geochemical Modeling, User's Manual, Waterloo Hydrogeologic, 2017.

75. Wibagiyo, Indroyono, Alip, Bungkus $P$, Haryono. Leakage investigation using radioisotope technique at Ngancar dam, Wonogiri. Research and Development of Isotope and Radiation Applications, 1998.

76. Wright, D. E. Training Aids for Dam Safety: Evaluation of Seepage Conditions. Interagency Committee on Dam Safety. Bureau of Reclamation, 1990.

77. Zhao, M.; Wang, H.; Sun, X.; Zhang, Y. Comparison between the Isotope Tracking Method and Resistivity Tomography of Earth Rock-Fill Dam Seepage Detection. Engineering, Vol. 3, 389-399, 2011.

78. Zhongcheng, T.; Baohong, L.; Yingying, S. Applications of an Integrated Tracing Approach in Dam Seepage Investigation Flow in Porous Media, From Phenomena to Engineering and Beyond. International Forum on Porous Flow and Applications, 2008. 
PERIÓDICO TCHÊ QUÍMICA • www.periodico.tchequimica.com • Vol. 16 N. 31.

•ISSN 1806-0374 (impresso) • ISSN 1806-9827 (CD-ROM)•ISSN 2179-0302 (meio eletrônico)

(C) 2019. Porto Alegre, RS. Brasil

The Periódico Tchê Química (ISSN: 1806-0374; 2179-0302) is an open-access journal since 2004. Journal DOI: 10.52571/PTQ. http://www.tchequimica.com. This text was introduced in this file in 2021 for compliance reasons.

OPEN ACCESS. This article is licensed under a Creative Commons Attribution 4.0 (CC BY 4.0) International License, which permits use, sharing, adaptation, distribution, and reproduction in any medium or format, as long as you give appropriate credit to the original author(s) and the source, provide a link to the Creative Commons license, and indicate if changes were made. The images or other third-party material in this article are included regulation or exceeds the permitted use, you will need to obtain permission directly from the copyright holder. To view a copy of this license, visit http://creativecommons.org/licenses/by/4.0/. 